\title{
Digital Reconstructions of Sauropod Dinosaurs and Implications for Feeding
}

\author{
Kent A. Stevens and J. Michael Parrish
}

N RECENT YEARS, SAUROPODS HAVE been interpreted primarily as quadrupedal herbivores, with sympatric taxa differentiated in their feeding behavior presumably according to their dentition and feeding height in a quadrupedal stance (e.g., Fiorillo ı998; Upchurch and Barrett 2000). In order to generate detailed hypotheses concerning sauropod paleoecology, it is essential to start with as accurate a reconstruction of their body plans as can be afforded from their fossils. An accurate rendering of the life posture of a sauropod is necessary in order to determine the feeding envelope for each taxon in its conventional quadrupedal stance. We review here the body plan of several major sauropod groups, emphasizing the use of whole-body reconstructions to determine the approximate head height when the animal was standing quadrupedally, supporting its weight symmetrically from left to right, and holding the axial skeleton in an undeflected state. The undeflected state is termed the "neutral pose," defined geometrically, and analyzed on the basis of osteological determinants in extant vertebrates as a guide to their reconstruction for sauropods. Neutral position head height is one key point for analyzing variation in feeding behaviors across sauropods, another being variation in dentition; both are set against the backdrop of available fodder.

What was the relationship between a sauropod's preferred feeding height and the height at which its head was held when the neck was undeflected? A bridging assumption is necessary to relate these two parameters for an extinct species. The habitual feeding posture of a terrestrial herbivore can relate to the neutral position of its neck in three ways: (I) the herbivore can deflect its neck ventrally relative to the neutral position for browsing, or "browse by ventriflexion" (BV); it can raise its neck relative to the neutral position, or "browse by dorsiflexion" (BD); or it can feed at or near the neutral position of the neck, or "browse neutrally"(BN). As browsing behavior is not directly preserved in the fossil record, it is necessary to consider the phylogenetic and functional distribution of these three feeding models among extant tetrapods.

The form of browsing (BV, BD, or BN) is, in principle, independent of the neutral pose head height (relative to shoulder height) of a given 
herbivore. Many extant low browsers and grazers, such as Thomson's gazelle (e.g., Leuthold I977:table 2), deer, and horses, engage in BV feeding primarily, but not exclusively. In a neutral pose, their heads are held in a high position, presumably for vigilance during periods of inactivity (Walther 1969). Muscular effort is expended to lower the head to feed, increasing the tension on the epaxial nuchal ligaments. One argument posed against low browsing in sauropods, even in diplodocids, is that it would leave them vulnerable to attack (Paul 2000).

While the high head heights that gazelles and other fleet-footed herbivores maintain when inactive allow them to detect and flee approaching predators, flight from predation was not a practical option for sauropods, the speeds of which are generally estimated as being much slower than those of their most likely predators (e.g., Alexander I989; Thulborn I990). Today, large BN to BV megaherbivores respond to the presence of carnivores by charging (e.g., rhinos, hippos, elephants [Owen-Smith I988]) or indifference (e.g., elephants, hippos [Owen-Smith I988]).

The giraffe is of particular importance to this chapter, as it has been cited as an extant model for those sauropods, including brachiosaurids, euhelopids, and camarasaurids, that are sometimes reconstructed as giraffe-like (e.g., Paul I987:figs. I6, I7; Currie I987:figs. 2, 3; Christian and Heinrich I998), effortlessly feeding while in a cervical neutral position (BN browsing) with the head held high above the shoulders. We review the osteological basis for the elevation of the giraffe neck, then examine the validity of proposing such a posture for any sauropod. It should first be noted that, perhaps surprisingly, giraffes frequently browse by ventriflexion, with the head at or below shoulder height (Leuthold and Leuthold I972; Pellew I984; Young and Isbell I991; Woolnough and $\mathrm{du}$ Toit 200I). The elongate neck of the giraffe is not a simple consequence of vertical niche partitioning (Simmons and Scheepers I996). Pincher (I949) proposes that predation provided the selection pressure for limb elongation in giraffes, and that neck elongation secondarily provided the ability to drink and reach low fodder.

There are many other modern examples of herbivores with neutral head height taller than the shoulders that primarily engage in browsing by ventriflexion, including many cervids, rhinoceratids, and equids (e.g., Leuthold I972; Owen-Smith ig88). There are also modern herbivores that have the head situated much lower in neutral position, again relative to shoulder height, which engage in $\mathrm{BN}$, such as some large bovids and other cervids such as the greater and lesser kudu (e.g., Leuthold I972; Owen-Smith I988). We are, however, unable to find examples of extant herbivores with heads well below shoulder height in neutral position that predominantly feed quadrupedally in a BD position.

If vigilance were not a factor for sauropods, then it might be inferred that the neutral pose would be related closely to their preferred feeding heights. Indeed, as we show, the neutral pose for some sauropods places the head very low to the ground. A sauropod with shorter forelimbs than hindlimbs and a steadily descending neck that brings the head to nearground level certainly appears well suited for $\mathrm{BN}$ (and BV) browsing, without compromise to vigilance, and less adapted to BD. Large extant grazing herbivores, such as bison, that hold their head closer to feeding height (e.g., Leuthold I977:table 2) are perhaps better analogues for those sauropods with low head height in neutral position.

Osteologically based reconstruction of neutral head height provides some refinement on the question of sauropod feeding behavior, when combined with consideration of whether a given taxon browsed by ventriflexion, by dorsiflexion, or near the cervical neutral position. We suggest that careful analysis of the osteologically defined neutral pose along the axial skeleton is an indicator of the mean feeding height of the sauropods, particularly as they do not, in any of the sauropod taxa we have examined, place the necks in a giraffelike high slope with heads held high, a position consistent with 
a predominant state of vigilance. As reviewed below, neutral pose reconstructions suggest that most sauropods would have their necks held horizontally or subhorizontally when not actively feeding or otherwise raising their heads.

\section{THE NEUTRAL POSE AS A BASIS FOR ESTIMATING FEEDING HEIGHT}

In describing the sauropod body plan, it is useful to start by establishing the height of the acetabular axis above ground level. Fortunately, maximum hindlimb length can often be reconstructed with some confidence, with the primary unknowns being the precise amount of cartilage separating the limb elements and the degree of flexure at the knee (e.g., Paul i987; Bonnan 200I). With the femoral heads inserted into their associated acetabula, the acetabular axis constitutes a pivot point for the whole-body reconstruction-a fulcrum about which the axial skeleton tilts depending on a given reconstruction of the trunk. The literature presents a range of interpretations regarding the arch to the span of vertebral column that supported the trunk. The degree of flexure of the arch is important here, for the greater the curvature, the lower the resulting head height. A given reconstruction of the dorsal vertebrae, with associated ribcage, forms an armature on which to place the pectoral girdles and forelimbs. In creating a skeletal reconstruction to quantitatively estimate mean feeding height, it is important to determine potential sources of variability in the appendicular and axial skeleton. These are reviewed below.

For modern quadrupedal herbivores, the characteristic posture associated with a standing pose is the starting point for exploring the range of feeding movements achieved by movements of the head and neck. A skeletal reconstruction of an extinct form, such as a sauropod, must similarly be posed in a neutral position as a basis for examining its characteristic feeding envelope. As considered here, the feeding envelope for a given taxon can be visu- alized as the extremes of head reach allowed by the flexibility of its neck (e.g., Martin I987:fig. 3; Stevens and Parrish I999). Note that the envelope, thus defined, reflects only variation in head position allowed by neck mobility, not the contributions of trunk and forelimb movements that undoubtedly broadened this envelope.

\section{THE NEUTRAL POSE OF THE APPENDICULAR SKELETON}

The nature of the articulations between the elements of the sauropod appendicular skeleton cannot be inferred entirely from osteology, although the hindlimb, because of the solid joints between sacrum and pelvis, is better constrained than the forelimb and pectoral girdles, which have no osteological connection to the axial column.

Whereas hindlimb length determines the height of the caudal end of the dorsal vertebral column, forelimb length only defines the height of the glenoid; the inferred height and slope of the anterior part of the trunk depend on the position and orientation of the scapulae on the ribcage and the degree to which the dorsal vertebral column is arched.

In extant quadrupeds, pectoral girdles do not have bony articulations with the trunk but, instead, are suspended from the thorax by musculature and soft tissues. While the presence of subtle depressions in the dorsal ribs in some sauropods such as Apatosaurus and Diplodocus provide some indication of the position and the alignment of the scapulocoracoid (Parrish and Stevens 2002b), determining its precise location requires considering the scapulocoracoids within the context of the overall function of the girdles, ribcage, and forelimbs.

Changing the relative height and inclination of the scapulocoracoid on the trunk can result in significant differences in the height of the cranial end of the thorax, with a corresponding change in head height (Stevens and Parrish 2005a). Early sauropod mounts differed in the orientation of the pectoral girdles relative to the ground, and thus, indirectly, in the angle of the scapula 
relative to the cranial part of the dorsal vertebral column. For instance, Gilmore (I936:pl. 34) placed the scapulae of Apatosaurus in a subhorizontal orientation, nearly parallel to the anterior dorsal column, whereas Osborn and Mook (I92I) placed the scapulae of Camarasaurus in a far more vertical orientation. The effect of shoulder girdle placement on the overall reconstruction can be appreciated by comparing the illustrations of the Apatosaurus in Gilmore (1936:pl. 34) versus McIntosh et al. (1997) or those of the Diplodocus mounted at the Carnegie Museum of Natural History (e.g., McGinnis I982:68-69) versus that at the Senckenberg Museum in Frankfurt (e.g., Beasley 1907). The effect of variation in shoulder girdle placement is also apparent below in digital reconstructions of Brachiosaurus brancai, in combination with variation in dorsal vertebral column curvature.

A range of interpretations has also been proposed for the articulation of the elements of the sauropod forelimbs, ranging from a vertical, columnar arrangement (e.g., Christian et al. I999) to partial flexure of the limbs (e.g., Janensch $1950 \mathrm{~b}$ ), resulting in a range of heights and locations for the humeral head. Most recent investigators (e.g., Bonnan 200I; Christian et al. I999; Wilhite 2003) predict minimal flexion of the elbow during standing, in keeping with the columnar forelimb posture of extant graviportal animals, but some reconstructions (e.g., the Humboldt Museum mount of Brachiosaurus [Christian et al. I999:fig. I]) depict a more reptilian sprawling pose (e.g., Christian et al. I999).

\section{THE NEUTRAL POSE IN THE AXIAL SKELETON}

The neutral pose of the axial skeleton is strongly constrained. The presacral vertebral column in sauropods is characterized by opisthocoelous central articulations, a character shared with many large herbivorous modern quadrupeds such as rhino, giraffe, horse, and camel. Opisthocoely, fortunately, provides particularly strong osteological clues to the state of neutral position.

Presacral intervertebral articulation involves synovial joints between centra and between left and right pairs of zygapophyses. Dorsoventral and mediolateral angular deflection results in gliding contact between the zygapophyses that limit axial rotation (Stevens and Wills 200I). The postzygapophyses are displaced posteriorly relative to their associated prezygapophyses during dorsiflexion and anteriorly during ventriflexion. The zygapophyseal facets are superimposed and centered in a state of neutral deflection.

The state of null deflection is also apparent at the central synovial capsule. The condyle, inserted deeply within cotyle, is surrounded by a broad circumferential ligamentous capsule. Within the capsule, the articular facets are closely spaced in modern vertebrates with opisthocoelous centra. In a rhino, for instance, the separation between cotyle and condyle is only a few millimeters, and in the giraffe, whose cervical vertebrae are also strongly opisthocoelous, the intervertebral gaps are only slightly wider, again, of the order of millimeters (B. Curtice, pers. comm. 200I, pers. obs.). Note that this close intervertebral separation may not be apparent from cursory observation. The capsule is substantially wider than the intervertebral separation, of course, to accommodate the displacement undertaken by the cotyle during deflection. Articulated sauropod cervical vertebral series are likewise very closely spaced, in all instances we have examined.

In modern vertebrates, dorsiflexion separation between the cotylar and the condylar margins of the capsule increases ventrally (and diminishes dorsally), placing the surrounding ligaments in progressively greater tension ventrally. Conversely, in ventriflexion, the separation and ligament tension increases dorsally (and diminishes ventrally). In a state of neutral deflection the margins of the associated cotyle and condyle are parallel; the gap is uniform around the perimeter of the synovial capsule, thus providing a second osteological indictor of neutral deflection. When undeflected, the posterior edge of the cotyle is parallel to the attachment scar surrounding the condyle, corresponding to the state of minimal stress on the synovial capsule. 


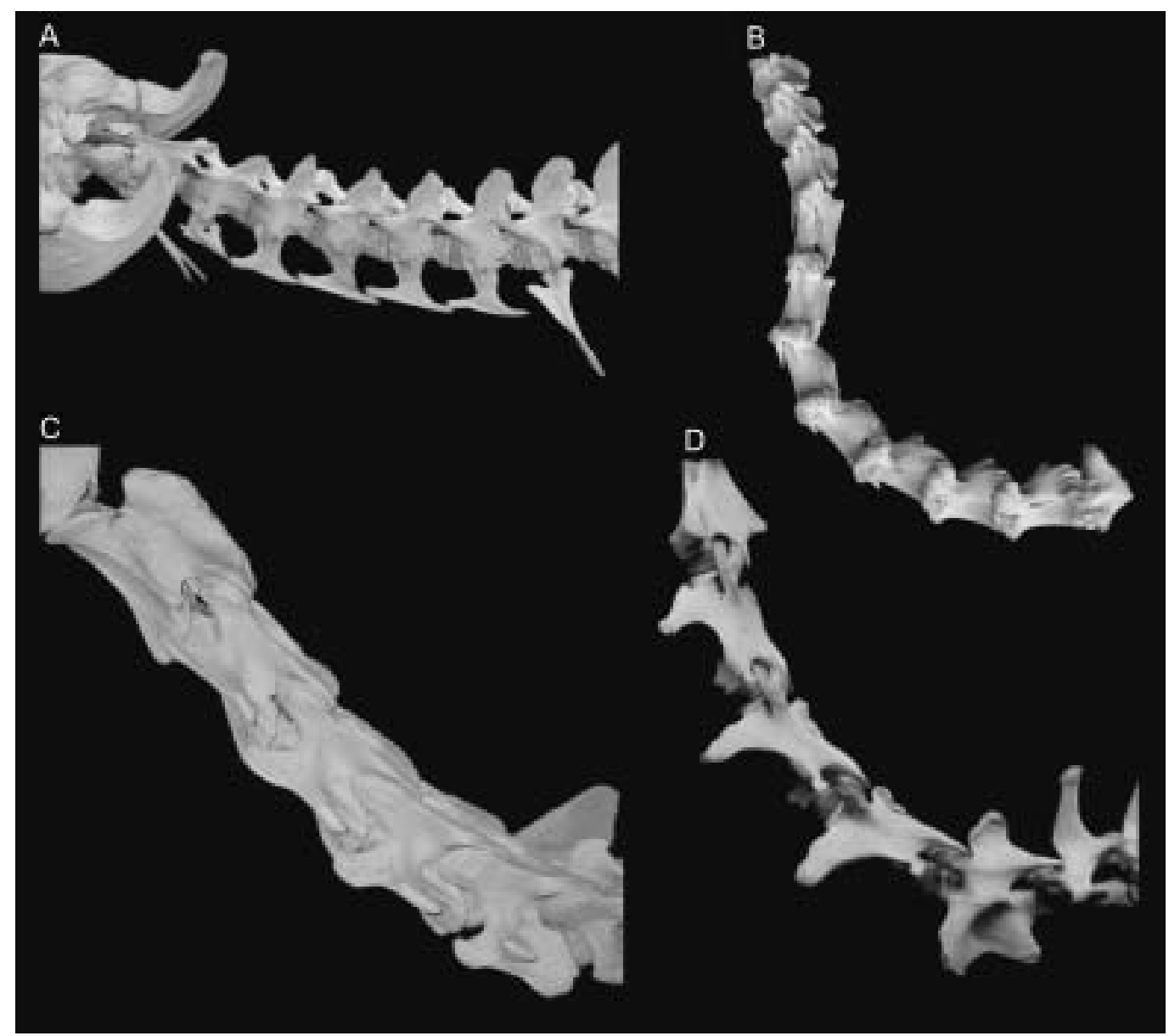

FIGURE 6.1. The cervical vertebral columns of articulated skeletons of (A) crocodilian (Gavialis gangeticus), (B) turkey (Meleagris gallopavo), (C) horse (Equus przevalskii), and (D) camel (Camelus dromedarius), each mounted in the undeflected, or "neutral," pose wherein apposed pre- and postzygapophyses are aligned and centered, and simultaneously, the margins of cotyle and condyle at each intervertebral joint are parallel. In each case, the neck in this undeflected state is naturally curved in the manner characteristic of that animal.

When the central articulation is undeflected according to the above criterion, the associated pre- and postzygapophyses are also undeflected (i.e., superimposed and centered). That is, the two criteria are satisfied simultaneously (fig. 6.I) in all extant vertebrates that we have observed. Their redundancy is particularly useful in reconstructing the neutral pose for vertebrae that are missing their zygapophyses (see the Brachiosaurus brancai reconstruction below). When successive vertebrae are placed in neutral position, joint by joint, the vertebral column forms the intrinsic curvature characteristic of the given extant animal.
When the vertebrae of extant mammals are placed in neutral pose, they replicate their habitual, characteristic posture (figs. 6.I, 6.2). For instance, in neutral pose, the neck of the camel exhibits its familiar catenary shape, and the sharp change in angulation observed at the base of the neck of the giraffe is clearly visible (fig. 6.2). Likewise, the sigmoid curves in the necks of theropod dinosaurs, including extant birds (fig. 6.IA), are associated with an undeflected neck and derive from the geometry of the vertebrae. Therefore, the neutral pose of the cervical vertebral column, and the cranial end of the dorsal vertebral column, 
FIGURE 6.2. The steeply ascending neck characteristic of the giraffe arises in the undeflected state, not by bending of the neck. Photographs of vertebrae $\mathrm{C}_{4}-\mathrm{TI}$ of an adult giraffe are placed in neutral position. Transparency is utilized to show the insertion of each central condyle within the cotyle and the overlap and alignment of the zygapophyses. The characteristic neck elevation derives from wedge- or keystone-shaped centra, especially apparent in the sixth and seventh cervical vertebrae. (Individual photographs courtesy of Brian Curtice.)

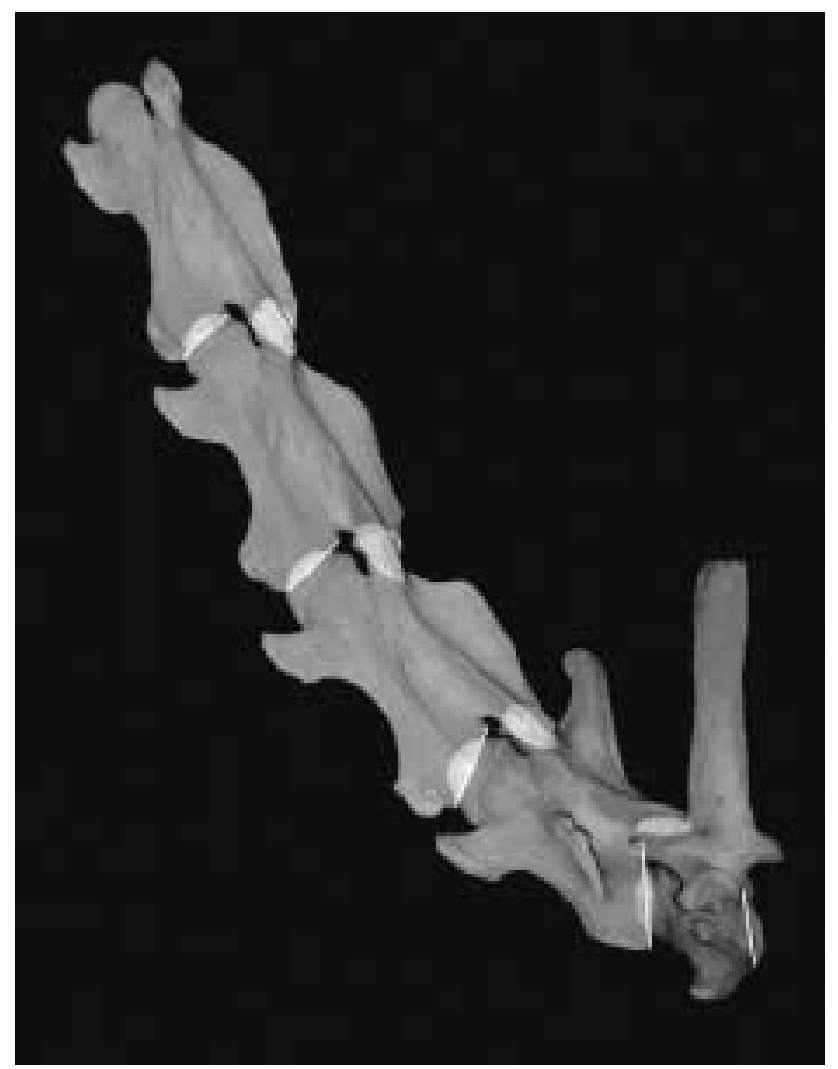

can be shown to be consistent with the preferred head height in a variety of extant quadrupedal herbivores, and thus we consider it a robust predictor of preferred head position in sauropods as well.

The cervical and anterior dorsal vertebrae of sauropods are strongly opisthocoelous, with prominent condyles associated with deep cotyles (figs. 6.3, 6.4). Articulation of axial elements in sauropods is geometrically similar to that in many extant vertebrates, allowing inference of their neutral or undeflected state to be made with some confidence.

Given the commonality in morphology of the articular facets of sauropod cervical vertebrae and those of a wide range of extant vertebrates, these criteria are presumed to hold for the cervical vertebrae of sauropods as well, permitting the reconstruction of their undeflected state and, hence, their intrinsic curvature.

\section{RECONSTRUCTING SAUROPOD CERVICAL COLUMNS}

\section{METHOD}

The neutral pose of a vertebral column can be reconstructed by creating a composite of lateral view illustrations or photographs, all depicted at the same scale, placed such that each successive pair of vertebrae is in neutral deflection. This method has long been used in traditional axial skeleton reconstructions (e.g., Osborn and Mook I92r:fig. 28). To introduce the technique, consider a pair of platycoelous centra. The apposed central facets are parallel to one another when the intervertebral joint is undeflected, hence their margins also appear parallel when viewed laterally. This neutral alignment is readily reconstructed graphically by twodimensional rotation, translation of images of the two vertebrae (e.g., using layers in Photoshop) 


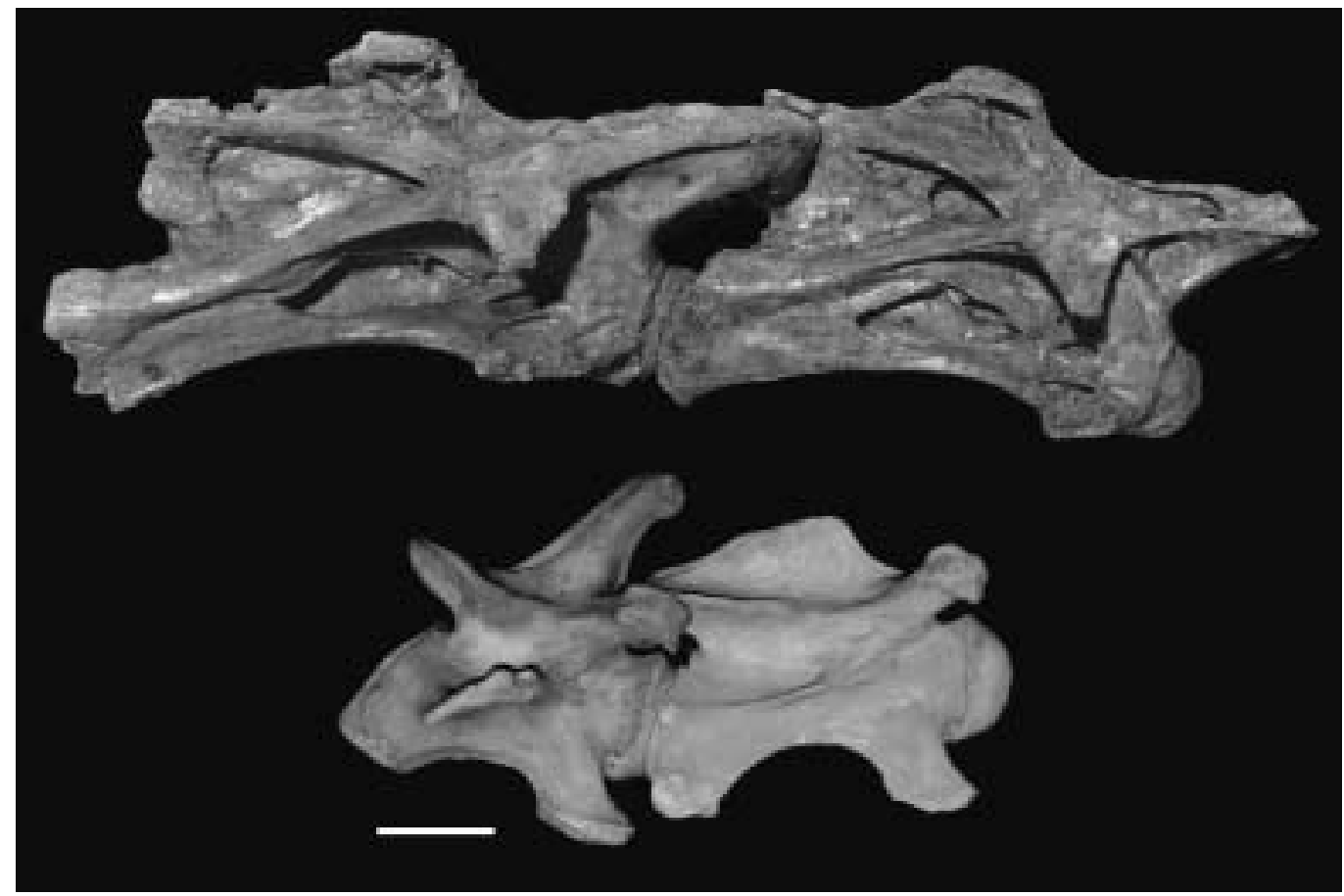

FIGURE 6.3. Intervertebral articulation in the neutral pose for the sauropod Brachiosaurus brancai (Top, cervical vertebrae $\mathrm{C}_{4}$ and $\mathrm{C}_{5}$ of the Humboldt Museum specimen SI) and for a giraffe (Bottom, cervical vertebra 7 and first thoracic vertebra), shown at the same scale. Note the similarity in articulation geometry, both being strongly opisthocoelous with condyles of circular profile making the center of rotation for dorsoventral flexion unambiguous. The relatively larger zygapophyses of the giraffe are closer to the center of rotation and thereby permit a greater angular range of motion. Scale bar equals io $\mathrm{cm}$. (Brachiosaurus and giraffe photographs courtesy of Christopher McGowan and Brian Curtice, respectively.)
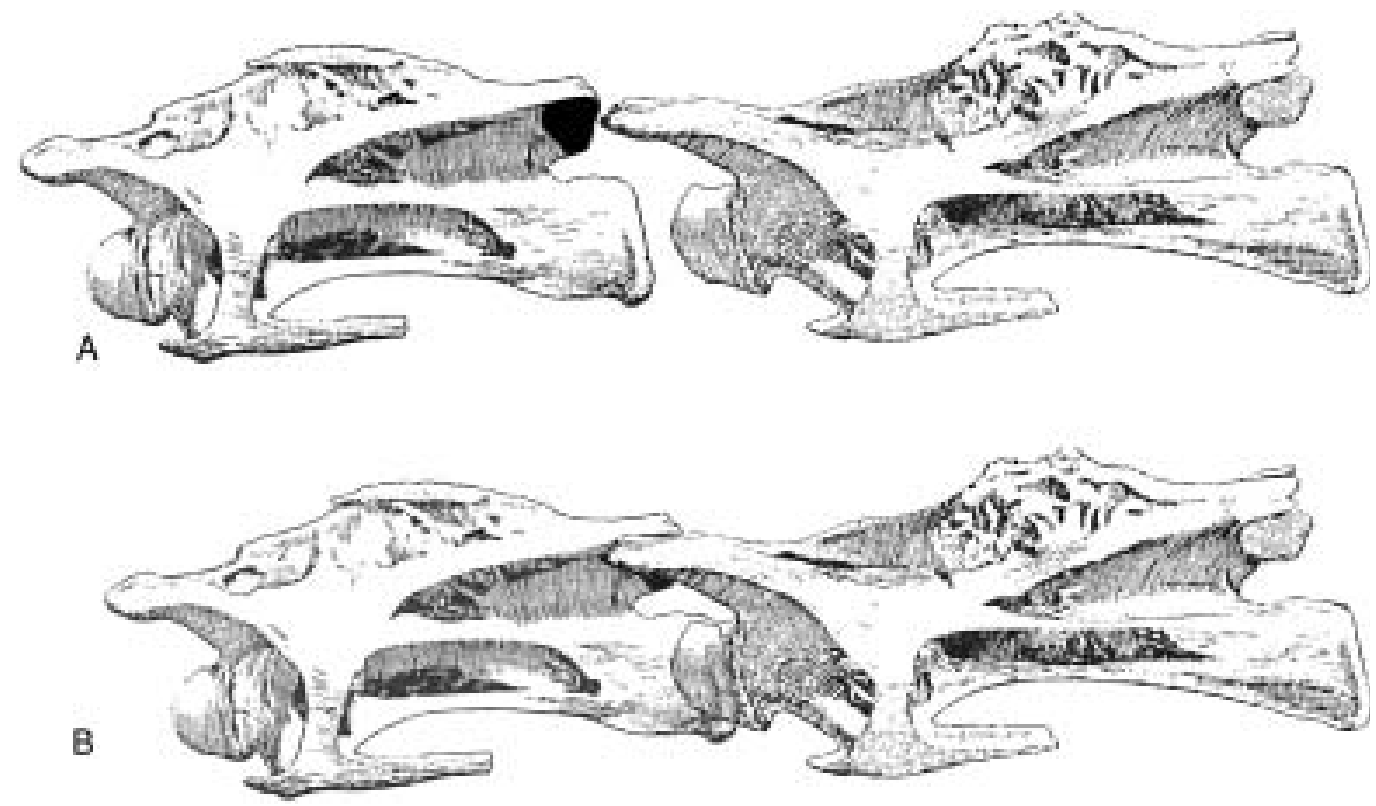

FIGURE 6.4. Cervical vertebrae $\mathrm{C}_{4}$ and $\mathrm{C}_{5}$ of Brachiosaurus brancai specimen SI (Janensch I950a: figs. 34, 37). In (A) the left postzygapophysis of $\mathrm{C}_{4}$ is shaded. In (B) the two vertebrae are composited in neutral position such that the pre- and postzygapophyses are centered and the margins of the cotyle and condyle at the central articulation are parallel. 
until the gap between centra is uniform and the zygapophyses are centered (i.e., both criteria of neutral position are met). When an entire vertebral series is composed from individual illustrations by this means, an intrinsic curve is often revealed, not due to flexion, but from centra that are sometimes subtly keystone- or wedge-shaped.

In sauropods, the articulations of the centra throughout the cervical vertebral column are strongly opisthocoelous. Fortunately, since the curvature of the sauropod neck is critical to understanding their paleobiology, opisthocoely helps, rather than hinders, the reconstruction of the neutral state of deflection. With condyle inserted into cotyle and placed in an undeflected state, the postzygapophyses are centered above prezygapophyses, and the posterior margin of the cotyle is parallel to the attachment scar of the synovial capsule surrounding the central condyle. In figure 6.4, line drawings of two cervical vertebrae of Brachiosaurus brancai have been composited into neutral position according to these criteria. Note that transparency reveals the insertion of the condyle within cotyle and the centering of the zygapophyses.

A second method is conceptually similar but performed three-dimensionally. Neutral pose can be determined by direct manipulation, as part of a process of exploring the range of motion in the axial skeleton. Although a pair of vertebrae, or even a complete neck, of an extant animal can be articulated and manipulated, sauropod vertebrae are not only unwieldy, but usually too distorted to allow proper rearticulation and manipulation. An alternative is to create digital representations of the vertebrae, which can then be articulated and posed virtually in three dimensions. A parametric skeletal modeling approach, DinoMorph (Stevens 2002), has been developed and used to estimate the feeding envelopes of two diplodocids (e.g., Stevens and Parrish I999). For the present study, dimensionally- accurate digital skeletons of three sauropods are posed in neutral position to estimate mean feeding heights. In each case published dimensional data provide the basis for reconstructing the overall body plan, with the morphology of individual elements ranging from detailed to schematic. A hybrid approach is also used for the reconstruction of the cervical vertebral series: twodimensional reconstructions based on original artwork provide an estimate of the intrinsic curvature of the undeflected cervical vertebral column, which is then used to pose the neck of the digital three-dimensional model (Stevens and Parrish 2005a).

\section{RECONSTRUCTING NECK CURVATURE}

\section{DIPLODOCIDS}

Apatosaurus and Diplodocus were initially reconstructed with necks that were quite straight and extended from an arched back so that the necks descended gently from the shoulders (e.g., Holland I906:fig. 2). Usually the necks are depicted in a state of mild dorsiflexion at the base, which raises the heads to about shoulder height. Recent renditions of these two diplodocids often provide their necks with a more pronounced sigmoid curve, dorsiflexed caudally and ventriflexed cranially (e.g., McIntosh et al. I997:figs. 20.II, 20.I2; Wilson and Sereno I998:foldout I). Similarly, in the original skeletal reconstruction of the diplodocid Dicraeosaurus the neck was shown in a pronounced sigmoid curve, abruptly dorsiflexed at the base and more gradually deflected downward cranially (Janensch I929:pl. I6). Unfortunately, it is difficult to determine from drawings to what extent the curvature was intended to depict active flexion versus a shape intrinsic to the neck.

The vertebrae in the original descriptions of the above diplodocids were rendered with excellent dimensional accuracy as detailed line drawings, and the original material was, in most cases, sufficiently undistorted to permit reconstructions of their neutral position by graphical compositing (Gilmore I936:pl. 24, 25; Hatcher I901:pl. 4, 6; Janensch I929:pl. I). These images were digitally scanned, then composited (fig. 6.5) to create reconstructions of the axial columns in neutral pose. The composites reveal that these diplodocids had remarkably straight 


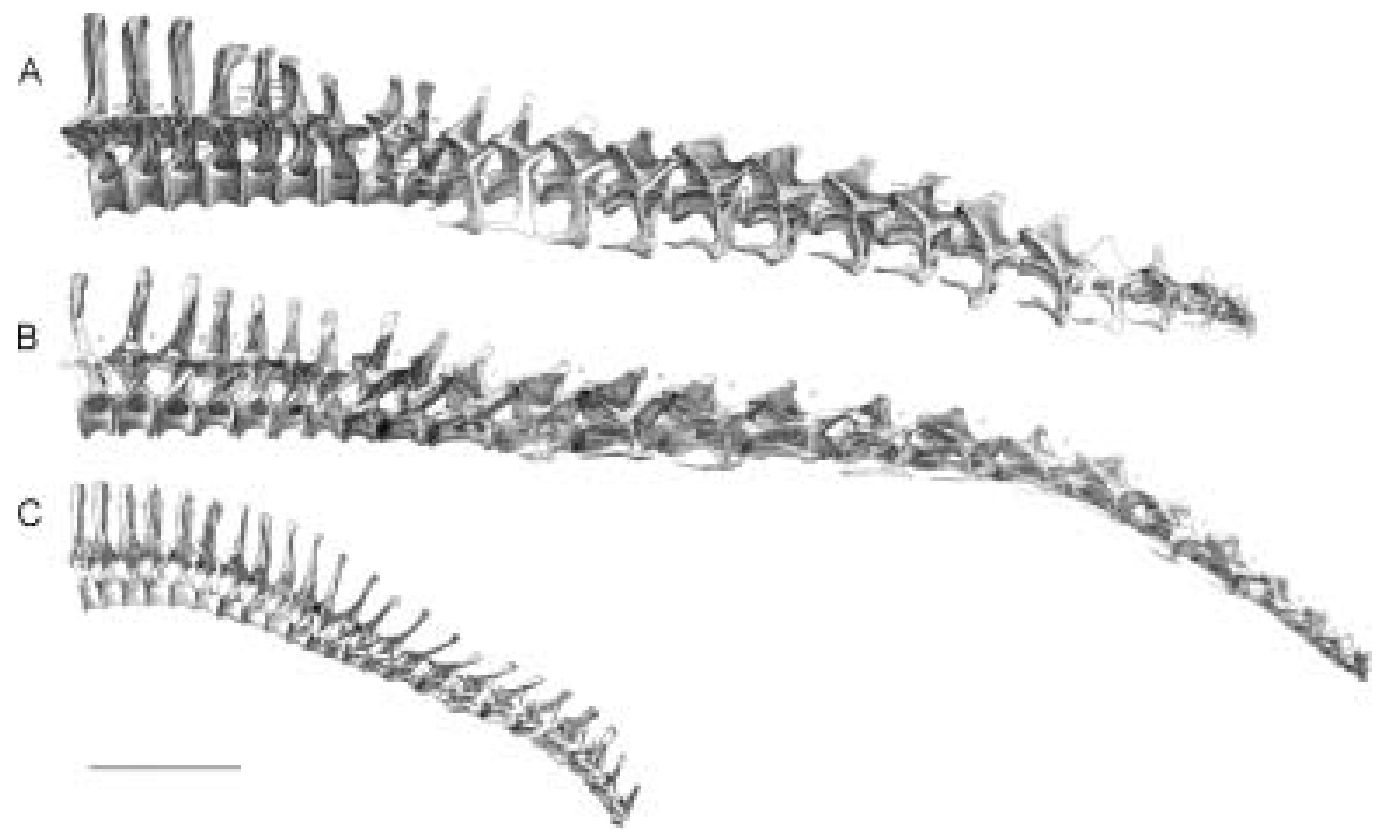

FIGURE 6.5. The presacral vertebrae of the diplodocids (A) Apatosaurus louisae, (B) Diplodocus carnegii, and (C) Dicraeosaurus hansemanni, composited from the original figures, placing each successive pair in neutral deflection (from Stevens and Parrish 2005b). Apatosaurus composite mirrored left-for-right for uniformity; all vertebral columns at the same scale. Scale bar equals I $\mathrm{m}$.

cervicodorsal transitions; their necks were straight extensions of their backs. The cervical columns of Apatosaurus and Dicraeosaurus show a gentle degree of ventral curvature in the neutral pose, which brings the head to a position well adapted to low browsing. The familiar sigmoid curve attributed to the neck of Dicraeosaurus (Janensch I929:pl. I6) was certainly within the limits achievable by dorsiflexion at the base and ventriflexion more cranially, but this pose was not reflected in the osteology of the neck. But presuming that the osteologically determined neutral pose was also the habitual posture for Dicraeosaurus, it usually held its head close to ground level, in common with other diplodocids, but at a steeper angle due to its relatively shorter neck.

\section{BRACHIOSAURUS AND OTHER SAUROPODS OFTEN DEPICTED AS GIRAFFE-LIKE}

The original reconstruction of Brachiosaurus (Janensch I950b:pl. 6-8) shows remarkable similarity to the modern giraffe, in part because of its tall limbs and ascending dorsal column but, especially, as a result of the neck that rises steeply at its base. The osteological basis for such a posture is reviewed here. This giraffe-like posture is even more dramatic in some reconstructions of Euhelopus and Camarasaurus, which are also considered.

Most reconstructions of Brachiosaurus provide the sauropod with a steeply upturned neck and depict the cervicodorsal vertebrae as wedge-shaped, with centra longer ventrally than dorsally, much as those at the base of the neck in the giraffe. Figure 6.6 shows in detail the cervicodorsal region as originally reconstructed, plus three subsequent depictions, all of which can be compared with a detailed figure of the original fossil material in this critical region.

Accurate line drawings of the available vertebrae of Brachiosaurus brancai were provided by Janensch (I950a:figs. I4-49). The lateral views are amenable to composition into a reconstructed column, for both specimen SI 


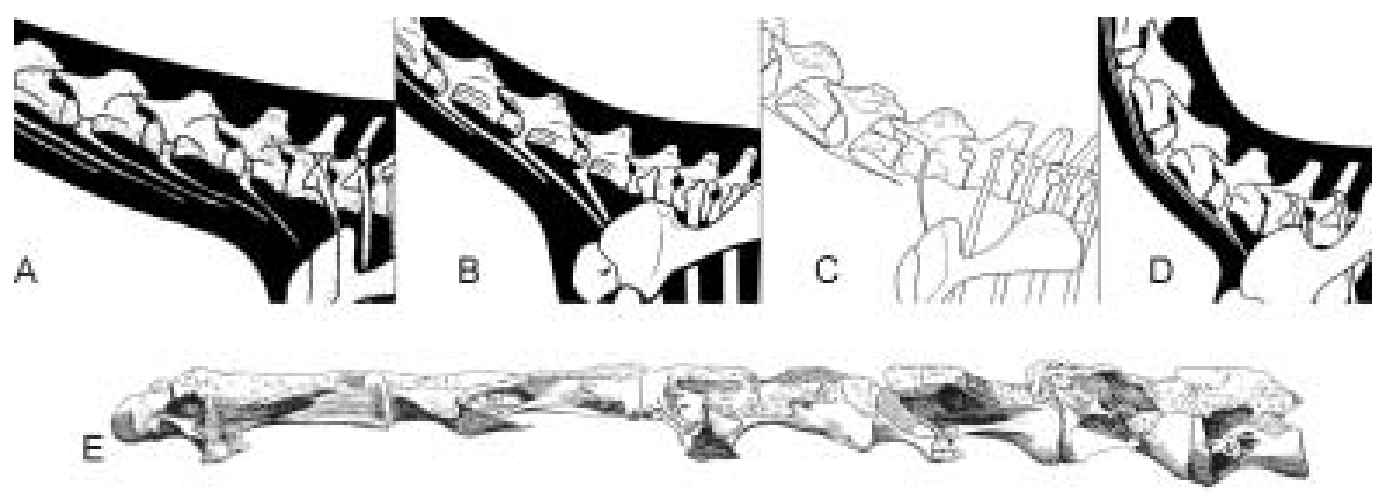

FIGURE 6.6. Details from four depictions of Brachiosaurus brancai: (A) Czerkas and Czerkas (I991:I32); (B) Wilson and Sereno (I998:foldout I); (C) Janensch (I950b:pl. 8); (D) McIntosh et al. (I997 fig. 20.I6). Note the differing degrees to which the cervicodorsal region is depicted as upcurved between the posterior of D2 and the posterior of Cio. This region, in (A) is curved merely $5^{\circ}$, while the same region is curved $68^{\circ}$ in (D) largely due to illustrating the centra as if they were distinctly wedge- or keystone-shaped (longer ventrally than dorsally). In (A) approximately $2^{\circ}$ of the curvature is due to keystoning, the rest presumably resulting from dorsiflexion. In (D) approximately $48^{\circ}$ is accumulated due to the shape of the centra, especially $\mathrm{C}_{2} 2$ and $\mathrm{C}_{13}$, and approximately $20^{\circ}$ reflects dorsiflexion, which further contributes to the near-vertical posture favored by that illustrator. Compare with original illustration (E; from Janensch i950a:fig. 49) of cervicals Cio-Ci3 plus first two dorsals, where no wedge shape is apparent.

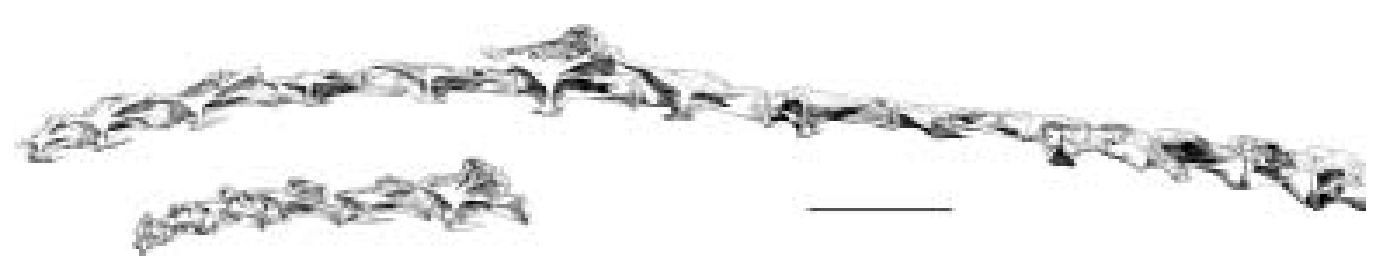

FIGURE 6.7. Neutral pose reconstructions of Brachiosaurus brancai specimens SII (Top, C3-D2) and SI (Bottom, C2-C7) from individual line drawings (Janensch I950a:figs. I4-49). SI is mirrored left-for-right to facilitate comparison with SII (from Stevens and Parrish in 2005b). The slight ventral curvature in neutral position appears intrinsic to Brachiosaurus and is consistent with head-down feeding. Note that vertebrae CIO-D2 of SII were collinear in situ, and while the neural arches were ablated, the centra show no keystoning or other osteological evidence to support a giraffe-neck interpretation (see also fig. 6.6). In fact, the partially exposed ventral surface of the central condyle of $\mathrm{D} 2$ is evidence of some dorsiflexion between Di and D2. Scale bar equals I $m$.

(vertebrae $\mathrm{C}_{2}$ through $\mathrm{C}_{7}$ ) and specimen SII (C3 through D2). Cranially, both exhibit the gradual ventral curvature in Dicraeosaurus (fig. 6.5). In specimen SII, although the neutral arches were not preserved caudal to C9, the central articulations provide clear evidence for the neutral deflection between subsequent pairs of vertebrae from the midneck to the second dorsal (Fig. 6.7). The result is a remarkably straight neck at the base, quite contrary to most restorations of this taxon (but see Czerkas and Czerkas I99I:I32). Properly restoring the neck of Brachiosaurus as extending straight from the shoulders, however, does not change its undisputed role as a high browser; see figure 6.8 .

Euhelopus zdanskyi (Wiman I929:fig. 3) is another sauropod traditionally depicted as giraffelike, with the life pose originally drawn having the same upturned neck as found in situ (fig. 6.9). The dorsiflexion at the base of the neck (primarily between Ci 6 and CI7 and between Ci7 and Di), however, reflects a "death pose" resulting from shrinkage of the nuchal ligaments. This conclusion is drawn from observing that the degree of dorsiflexion as measured between successive centra equals the angle of dorsiflexion at the zygapophyses 


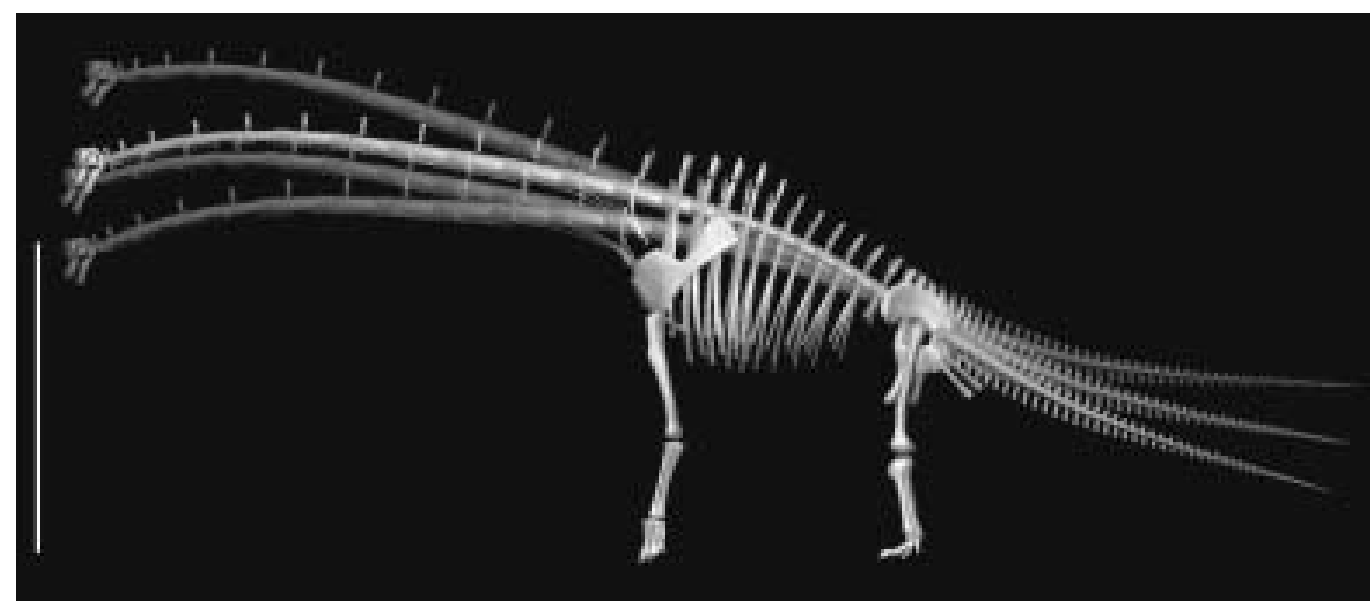

FIGURE 6.8. A DinoMorph model of Brachiosaurus brancai shows the effect on head height of pectoral girdle placement and dorsal column curvature. The neck curvature is held constant in the neutral pose derived from digital composites of the original steel engravings (fig. 6.7). The postcervical skeleton is based on specimen SII (Janensch I950a, I950b, I96I). Four alternative head heights result from combinations of high versus low arch to the dorsal column and high versus low placement of the pectoral girdles on the ribcages. The high arch and low pectoral girdle placement case is shown in full contrast, while the others are depicted at lower contrast. The highest head height is associated with the combination of low arch and low girdles. The lowest head height derives from the combination of high arch and high girdles, which brings the head only to shoulder height. Vertical scale bar equals $5 \mathrm{~m}$.
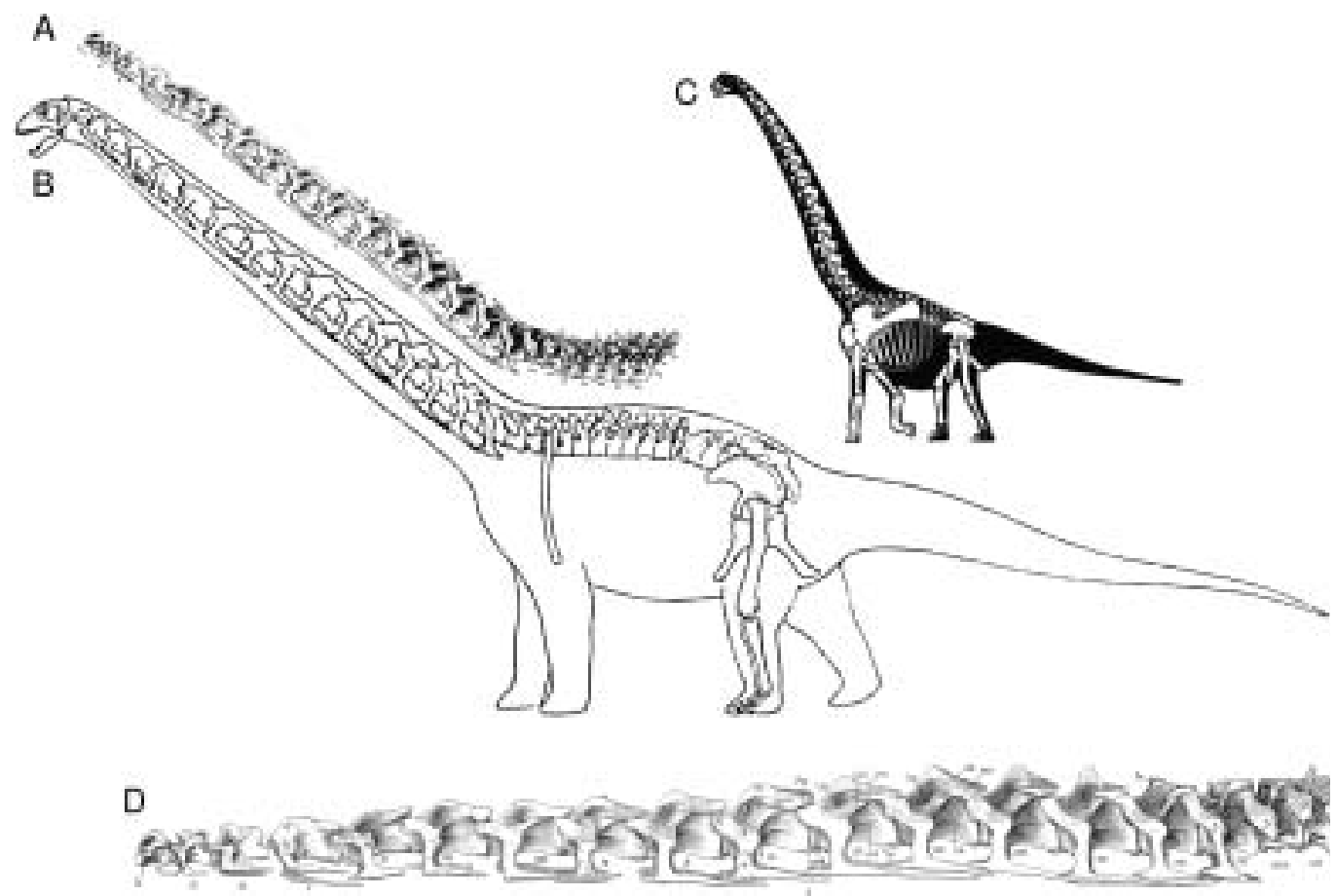

FIGURE 6.9. The original life reconstruction of Euhelopus zdanskyi (A) was depicted with a giraffe like neck, ascending with about $38^{\circ}$ of slope (from Wiman i929: fig. 3). The sharp curvature at the base of the neck replicated that of the original specimen as found in situ (B; from Wiman I929:pl. 3). In (C) (from Paul 2000: appendix A), the slope is increased to about $65^{\circ}$. With removal of the "death pose" dorsiflexion that is localized to the base of the neck (D; from Stevens and Parrish 2005b), the neck of Euhelopus emerged from the shoulder as a straight extension of the dorsals, sloping more or less downward depending on the arch of the dorsal column and the relative height of the (unknown) forelimb. The resultant low head height was similar to that of the diplodocoids and consistent with low browsing. 
(Stevens and Parrish 2005b). Removing this degree of dorsiflexion restores the neutral pose and Euhelopus is revealed to be a low browser, not at all giraffelike.

Similarly, the juvenile Camarasaurus at the Carnegie Museum (CMNHis338 [Gilmore I925:fig. 14]) also exhibits the extreme curvature of a death pose. The neck was preserved with the swanlike curvature that is now popularly portrayed in life reconstructions of this taxon. Examination of the original specimen reveals that many of the postzygapophyses are completely disarticulated from their associated prezygapophyses (Parrish and Stevens I998). Even if this condition could have been tolerated in life, such an extreme of dorsiflexion certainly did not constitute the neutral pose for the neck. Furthermore, quantitatively, unlike in Euhelopus, the angular deflection at the zygapophyses was generally greater than that at the centra, suggesting that the neck in neutral pose was at least partially ventriflexed, in common with our observation of other sauropod taxa. In summary, we have yet to find any sauropod with evidence of osteological adaptations for an upraised neck in the undeflected, neutral pose. Dorsiflexion could undoubtedly greatly increase the head height for feeding many meters above the ground, but the popular rendition of sauropods such as Brachiosaurus, Euhelopus, and Camarasaurus as giraffe-like is unwarranted.

Finally, we note that while the neutral pose represents the approximate center of a tetrapod's potential feeding envelope, the predominant feeding position is not necessarily the neutral position. As noted, many open habitat ungulates assume close to the neutral position while inactive yet frequently engage in BV feeding, often far from the neutral position. There are well-defined limits, fortunately, to how far the neck may deviate from the neutral position. Based on behavioral observations and manipulation of living and preserved necks of extant birds and mammals, we are confident that the feeding positions of sauropods in life would be limited by mechan- ical soft tissue constraints that might be violated taphonomically. In estimating the range of deflection that might have been achieved about the osteologically defined neutral position, we turn to extant vertebrates.

\section{ESTIMATING NECK FLEXIBILITY IN SAUROPODS}

In seeking modern analogues on which to base estimates of sauropod neck flexibility, potential candidates include long-necked vertebrates such as the ratite, giraffe, and camel. All have considerable mediolateral flexibility. A giraffe, for instance, can reach insects biting the base of its own neck. Some mammals achieve greater lateral angular deflection per vertebral joint than avians, having only 7 , compared to II to 25 , cervical vertebrae over which to distribute the curvature. Dorsoventrally, however, these long necks vary considerably in flexibility, with the giraffe showing little flexibility except at the cervical-dorsal transition, whereas the camel can touch the back of its head to its shoulder (Gauthier-Pilters and Dagg I98r:fig. 29).

With such a wide range of observed flexibility, there might appear to be little ground for postulating any particular range of neck flexibility in the sauropods. Specifically, it has been suggested (Sereno et al. I999) that estimating sauropod neck mobility based on the observed intervertebral limitations of avian cervical vertebrae (Stevens and Parrish I999; fig. 6.I0) might be too conservative in light of the camel's remarkable flexibility. In order to test the validity of the assumptions made regarding the neutral pose and estimates of the range of mobility in sauropods, we performed several comparisons between the observed ranges of movement in extant long-necked mammals and the amount of mobility produced by manually manipulating skeletonized and disarticulated specimens of the cervical columns of individuals of the same species (Parrish and Stevens 2002a). Independent studies involving the manipulation of extant ostrich are also consistent with our estimates regarding the angular constraints imposed by zygapophyseal synovial 


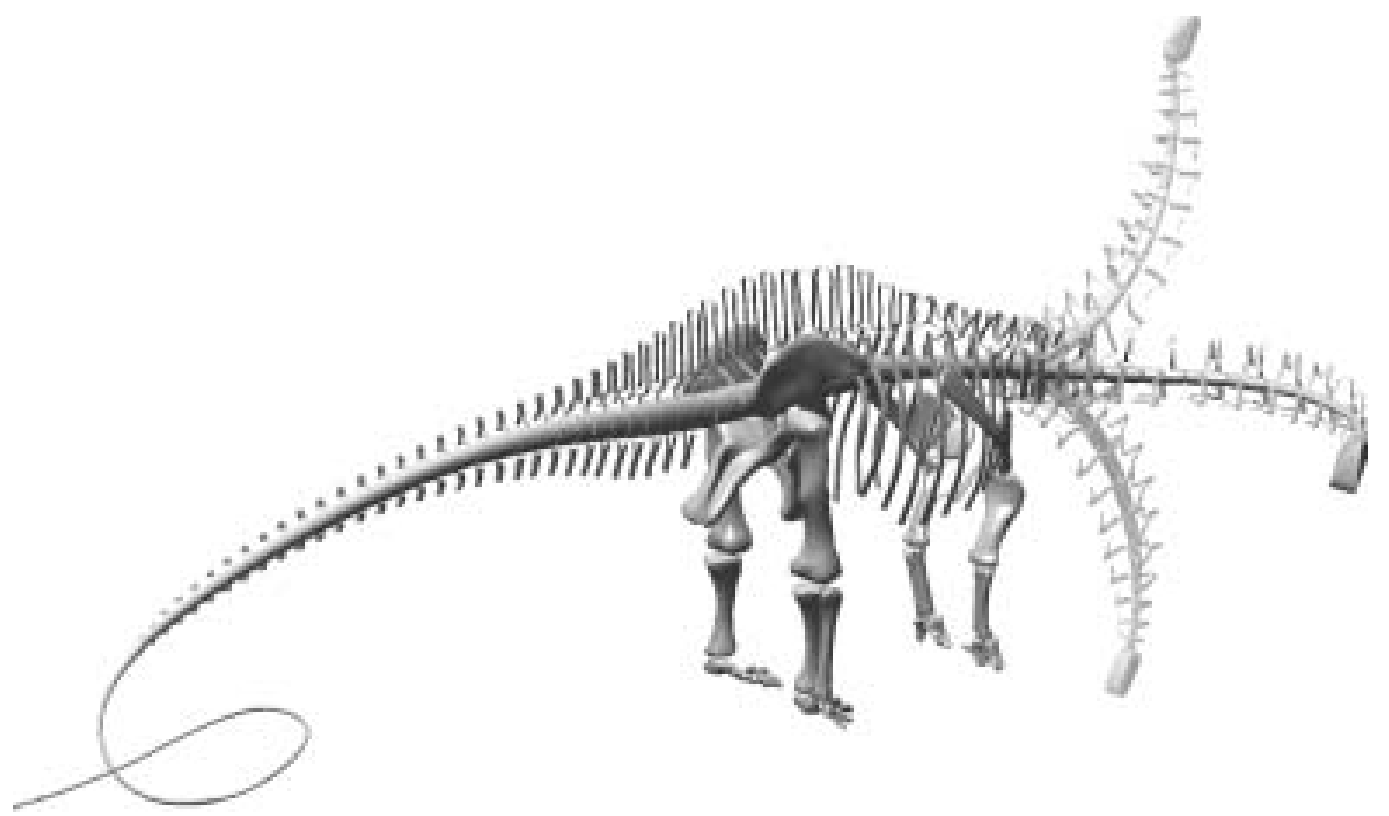

FIGURE 6.10. DinoMorph model of Apatosaurus louisae showing the extremes of dorsoventral motion and lateral flexibility estimated by Stevens and Parrish (I999). The three-dimensional skeletal model is based on Gilmore (I936) and data from Philip R. Platt (pers. comm. 2003). The neck of Apatosaurus was found to be capable of a substantial range of motion (see also fig. 6.I5), with more lateral and dorsal flexibility than the longer-necked Diplodocus, but it shared with Diplodocus the theoretical ability to lower its head below mean ground level, a potential adaptation for feeding on subaqueous plants from shore.

capsules (Wedel and Sanders I999). In avians, these synovial capsules limit displacement between associated pre- and postzygapophyses such that they remain overlapping, with a safety margin, throughout the range of motion. The remarkable dorsal flexibility of the camel neck is likewise achieved without zygapophyseal disarticulation (fig. 6.II). The elongate zygapophyseal facets provide sufficient travel to permit this extraordinary flexibility.

Neck flexibility in some extant vertebrates is delimited by osteological stops that prevent excessive displacement. In the domestic turkey, for instance, dorsiflexion causes the postzygapophyses to translate caudally until they contact the ascending base of the dorsal spine of the next vertebra, often nesting into a matching depression just posterior to the associated prezygapophyses medial to the paradiopophyseal lamina. The zygapophyseal pair is still articulated, that is, overlapping, at this limit. This mechanism operates unilaterally when dorsiflexion is combined with lateral deflection; for example, adding left lateral deflection causes the left postzygapophysis to eventually make contact, and at this limit both the left and the right zygapophyseal pairs preserve a safe degree of overlap. The osteological stop is present along most of the neck of the domestic turkey and the rhino, but in the horse, for example, it is apparent only at the base of the neck. The extreme dorsal flexibility of the camel is likewise limited by bony contact that prevents the neck from disarticulation (fig. 6.I2), despite the external appearance of disarticulation in the behaving animal.

Although a camel's death pose is achievable in life (Gauthier-Pilters and Dagg I98r:fig. 6o vs. 33), it bears reminding that the camel neck permits such flexibility by design and it is osteologically prevented from disarticulation in dorsiflexion. The flexion of the camel neck, while considerable at its limits, is delimited by the same biomechanical means as in avians and, by 


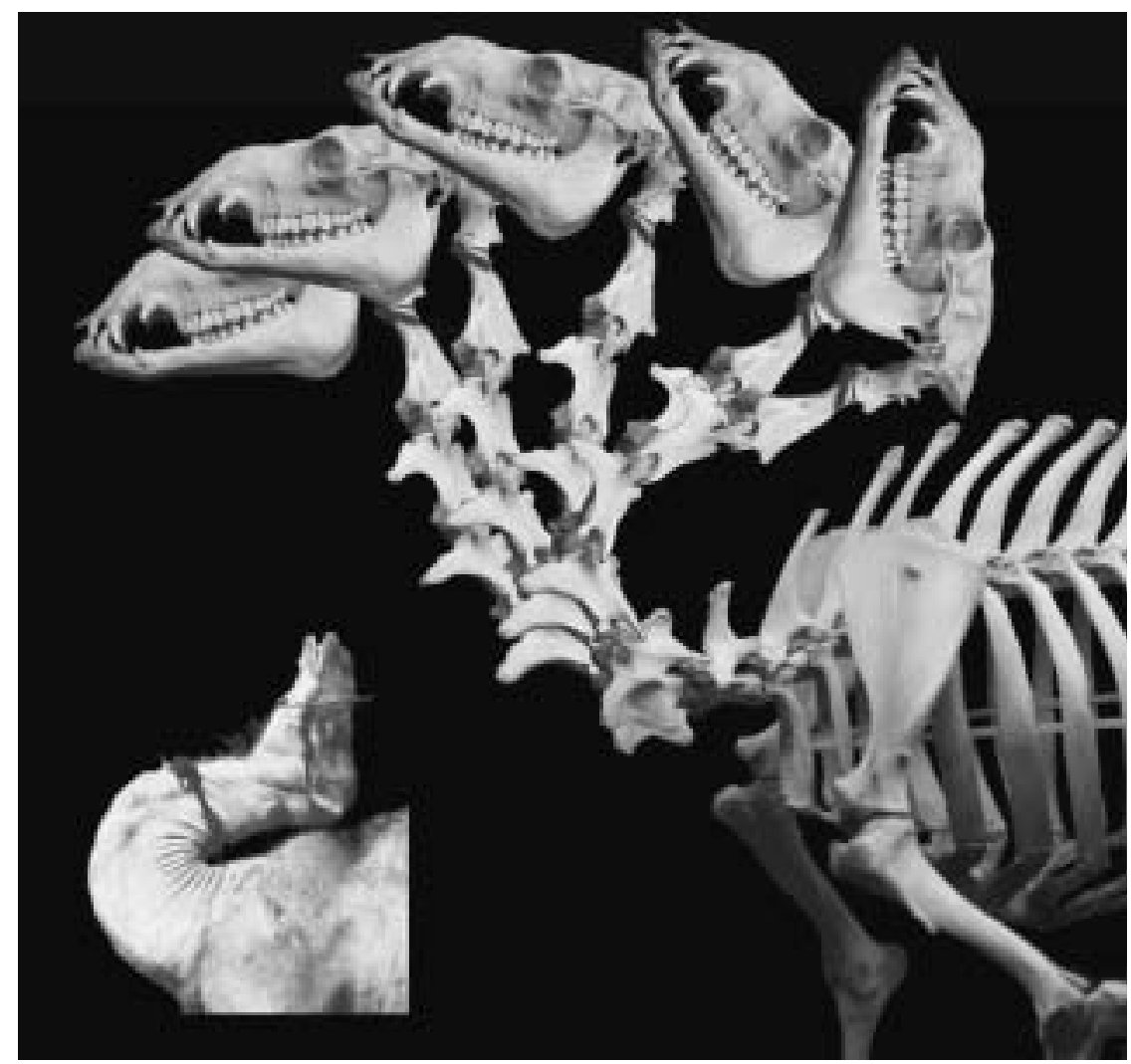

FIGURE 6.11. The remarkable dorsal flexibility of the camel's neck (inset; after Gauthier-Pilters and Daag I981:fig. 29) might suggest that sauropod necks were also more flexible than might be predicted based on birds, wherein the zygapophyseal synovial capsules limit the travel of the enclosed articular facets prior to disarticulation (cf. Stevens and Parrish I999; Sereno et al. 1999). The camel's flexibility, however, can be replicated without disarticulation between associated pre- and postzygapophyses. Dorsiflexion is in fact limited osteologically prior to disarticulation (see fig. 6.I2). The large angular deflection achieved per joint in the camel's neck is a geometric consequence of its elongate zygapophyses set close to the center of dorsoventral rotation.

analogy, in sauropods. However, the osteological features that limit dorsiflexion in many highly flexible extant taxa are not apparent, as far as we have observed, in sauropods.

The giraffe's restricted dorsoventral motion is also limited osteologically, both dorsally, as just described, and ventrally (B. Curtice, pers. comm. 200I; Parrish and Stevens, pers. obs.). It should be noted that the extreme lateral flexibility of the giraffe is "at the edge," with minimal overlap at the zygapophyses, and not protected by the osteological stops present in avian vertebrae. As in many vertebrates, the range of motion is further delimited by the ligamentous synovial capsules surrounding the zygapophyses, which become taut at a limit of displacement between zygapophyses. In avian cervical vertebrae, at the limits of travel the zygapophyses maintain roughly 25\%-50\% overlap (Stevens and Parrish I999; Wedel and Sanders I999).

The maximum displacement between zygapophyses permitted by the surrounding capsules translates to a maximum angular deflection. The cervical flexibility of the giraffe, the camel, and various avians has been found to be predictably related to the geometry of the zygapophyseal facets and their placement relative to the axes of rotation (figs. 6.II, 6.I3). Given the morphological similarities between avian and sauropod cervical vertebrae, Stevens 


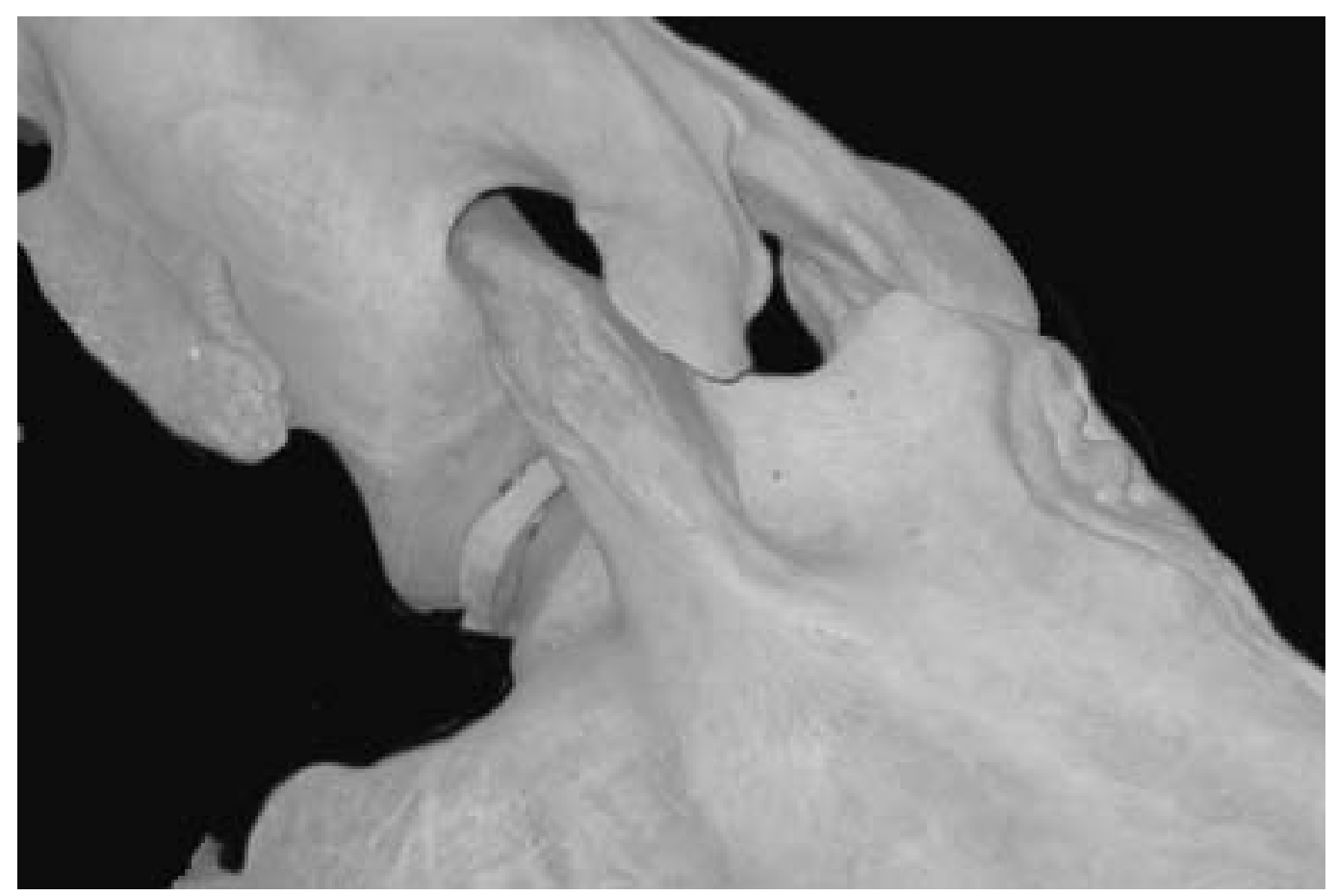

FIGURE 6.12. Dorsiflexion at the base of the neck in the camel is arrested osteologically prior to disarticulation at the zygapophyses. Postzygapophyses lock into depressions just posterior to the associated prezygapophyses at the limit of dorsiflexion.

and Parrish (I999) estimated the flexibility of two diplodocids, using dimensionally accurate models for the articular facets and centra and assuming that the zygapophyses were limited to a maximum displacement (or minimum tolerated overlap) based on that observed in avians (figs. 6.I3, 6.I4). The result was less overall range of motion than commonly expected, primarily in those regions of the neck where the relatively small zygapophyses would have allowed little excursion.

\section{ESTIMATING FEEDING HEIGHTS}

In neutral pose, the neck of every sauropod we have studied thus far has negligible curvature at the base and, at its cranial extent, a tendency to droop or curve ventrally. Determining the mean head height requires understanding the height and slope of the base of the neck, which in turn is determined by the reconstruction of the trunk. The precise degree of arching of the dor- sal vertebrae of most sauropods is as yet unknown, and the placement of the pectoral girdles is still a matter of some uncertainty as well. Nonetheless, the maximum effect of these factors on mean feeding height can be estimated for various taxa that have been modeled three-dimensionally.

The variation in head height resulting from differing expectations for pelvic girdle placement can be envisioned by similar triangles. Holding other factors constant, the head can be thought of as cantilevered at the end of the presacral column ahead, pivoted about the acetabular axis, and supported by the glenoid. The variation in head height is proportional to the ratio of rostrum-acetabulum distance to glenoid-acetabulum distance, typically about three times the variation at the shoulder. While there is significant uncertainty in the reconstruction of the pectoral girdles, this effect is compounded by the degree of the arch to the dorsal column (fig. 6.8). Clearly these differences do not 


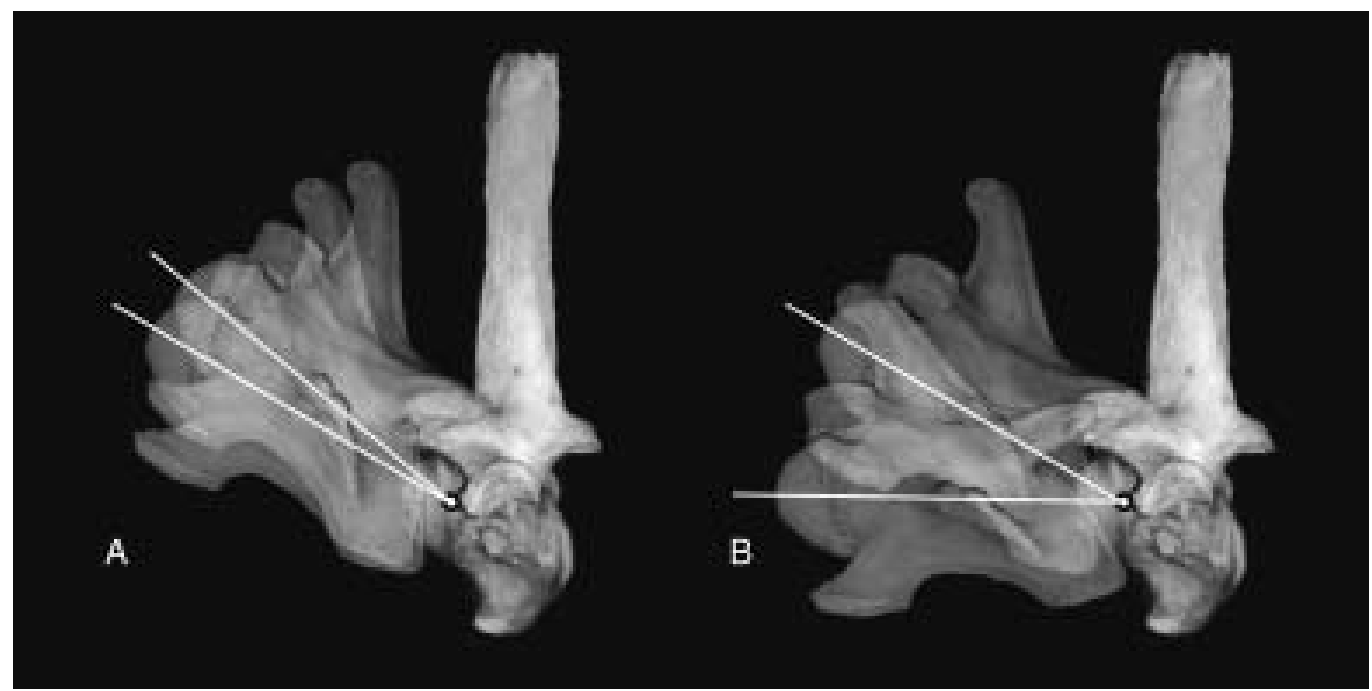

FIGURE 6.13. Giraffe dorsoventral range of motion for cervical vertebra $\mathrm{C}_{7}$ articulating on Tr. The center of rotation, as indicated, was estimated by a circular fit to the profile of the condyle of TI. In (A) dorsiflexion of approximately $9^{\circ}$ (relative to indicated neutral position slope) is limited osteologically when the postzygapophyses of C7 contact TI. In (B) ventriflexion of roughly $30^{\circ}$ is permitted while preserving substantial overlap (about 50\%) between zygapophyseal facets.

FIGURE 6.14. Diplodocus carnegii cervical vertebrae $\mathrm{CI}_{3}$ and Ci4 (after Hatcher I9or: pl. 4) showing estimated limits of the dorsoventral range of motion. In (A) the right postzygapophysis of $\mathrm{C}_{13}$ is shaded, and the midline of prezygapophysis of $\mathrm{C}_{14}$ is indicated along with the center of rotation for dorsoventral flexion at the center of curvature of the condyle of Ci4. In (B) the two vertebrae are placed in articulation and the dorsiflexion limit of $6^{\circ}$ is illustrated, defined as the angular deflection that reduces the zygapophyseal overlap to $50 \%$ (note that the anterior margin of the postzygapophysis of $\mathrm{C}_{3} 3$ is displaced anteriorly to the indicated midline). In (C) ventriflexion is limited to about $8^{\circ}$ (at which point the posterior margin of the postzygapophysis is displaced to the prezygapophysis midline).
A

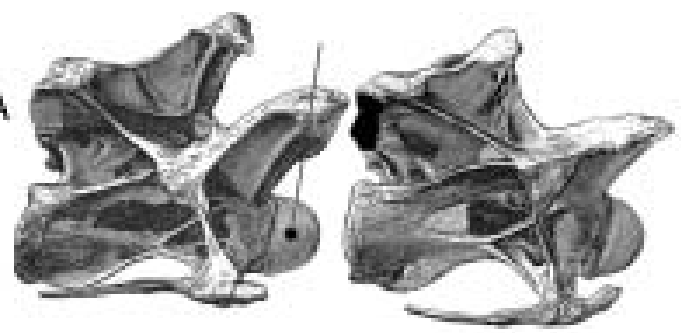

B

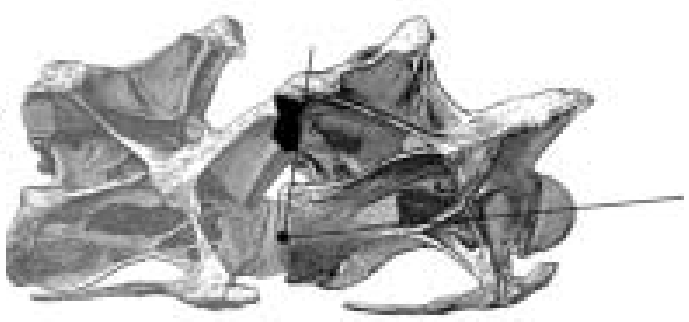

C

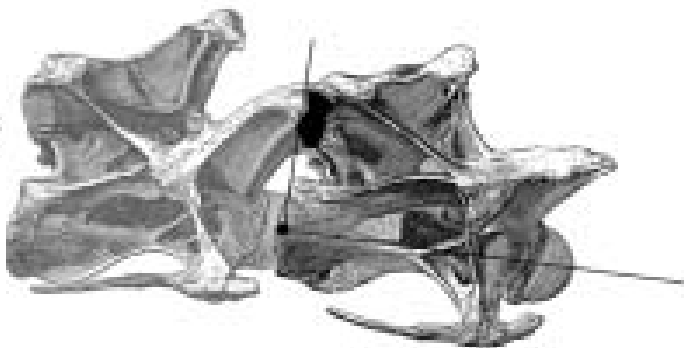




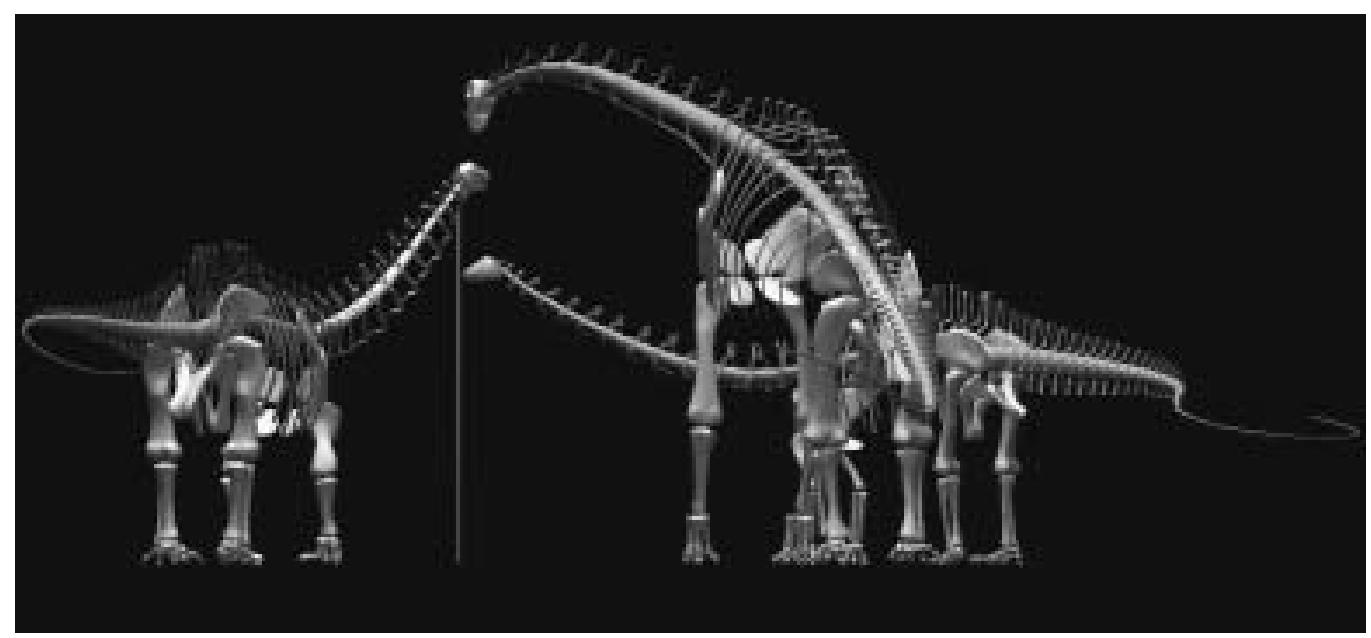

FIGURE 6.15. DinoMorph models of Brachiosaurus in neutral pose and Apatosaurus and Diplodocus maximally dorsiflexed, showing that the vertical feeding range of these three sympatric sauropods overlapped significantly: Apatosaurus could reach the neutral pose head height of Brachiosaurus, and Diplodocus, while less dorsally flexible, was capable of $>4-\mathrm{m}$ elevation. Vertical scale bar represents $5 \mathrm{~m}$.

categorically change the expectation for browse height, but they do have some consequences regarding conventional views on niche partitioning among sauropods. Based on DinoMorph simulations, Diplodocus was capable of reaching vegetation at least $4 \mathrm{~m}$ high, and Apatosaurus had sufficient dorsal flexibility to reach what we estimate to be the mean head height of Brachiosaurus (fig. 6.I5). On the other hand, Brachiosaurus could readily reach down to ground level (without the need to splay its legs giraffe-style), provided it had the modest ability to flex about $8^{\circ}$ ventrally in the proximal cervical vertebrae. Thus these two clades shared 4-6 $\mathrm{m}$ of vertical feeding range, which also appears to have overlapped those of camarasaurids (fig. 6.I5).

\section{FEEDING STRATEGIES AND PALEOECOLOGY}

In the last decade, many studies have addressed sauropod feeding, mostly from the standpoint of tooth morphology and microwear (Fiorillo I998; Christiansen 2000; Upchurch and Barrett 2000), jaw muscle reconstruction and cranial mechanics (Calvo I994; Barrett and Upchurch 1994; Upchurch and Barrett 2000), or bioenergetics (Farlow I987; Dodson I990).
Sauropod feeding is of interest for several reasons. First, as has been widely noted (e.g., Stevens and Parrish 1999), sympatry among sauropod genera is widespread, particularly in the Late Jurassic (although the recent study by Curry Rogers and Forster [200I] indicates that two or more sympatric species of sauropods may have occurred in Madagascar as late as the Late Cretaceous). Second, because sauropods are among the largest terrestrial herbivores that ever lived, understanding their bioenergetics is useful both in considering the scaling of metabolism in vertebrates and in examining the likelihood that sauropods, and other dinosaurs, were endotherms, were ectotherms, or had a unique metabolic physiology.

It is clear from the cranial and dental studies that significant differences existed among sauropod feeding mechanisms. Brachiosaurids and camarasaurids had broad, spatulate teeth that appear to have been optimal for biting off resistant vegetation, whereas the teeth of diplodocids and titanosaurs were more peglike in shape and probably functioned best in cropping or, perhaps, in stripping leaves from branches (Barrett and Upchurch I994). The recent feeding studies are unanimous in their assertion that no significant processing of food occurred in the mouths 
of any known sauropods, although the spatulatetoothed forms probably sliced their food when grasping it with their mouths rather than just pulling it off the branches.

Another topic of debate is the range of heights and, in particular, the maximum height at which a given sauropod taxon might have fed. Different workers have based their estimates of maximum feeding height on their assumptions regarding cervical posture. Upchurch and Barrett (2000) estimated the maximum browse height as the sum of shoulder height and neck length. In other words, their maximum browse height assumed a completely vertical neck. The reconstructions in McIntosh et al. (I997) approach this assumption as well. As discussed above, the results of our cervical studies suggest substantially lower maximum browsing heights. Head elevation was far from vertical, reaching only approximately $42^{\circ}$ above the horizontal in Apatosaurus and about $15^{\circ}$ in Diplodocus (fig. 6.I5). Since the curvature associated with dorsiflexion shortens the effective neck length, maximum browse height would be more accurately estimated as the sum of shoulder height plus roughly $40 \%-60 \%$ of the neck length. Maximum browse height might be of lesser ecological importance than mean browse height, however, given the prevalence of BV feeding in modern herbivores, where larger and taller taxa may capitalize on their ability to ventriflex (i.e., to reach down from their neutral feeding height) to obtain food resources when their preferred fodder becomes scarce (Daag and Foster i976; Leuthold r977).

Occasionally some sauropods (usually diplodocids [e.g., Bakker I986; Paul 2000]) have been depicted as standing tripodally, balanced on their hindlimbs and the proximal end of the caudal vertebral column, and thus as having the potential to reach far higher vegetation. If some sauropods were capable of assuming such a tripodal feeding posture, a far greater range of vertical niche partitioning would have been possible than if all sauropods were obligatory quadrupeds. Again, an accurate body reconstruction is a necessary prerequisite to estimating the additional height that might have been provided by a sauropod rearing up on its hindlimbs. The maximum feeding height, however, would be far harder to estimate, because the acetabulum height would no longer serve as a definitive anchor point.

The hindlimb stance would probably need to be widened to achieve stability, which in turn would lower the center of mass and the fulcrum about which the presacral trunk would pivot. Unless the back were flexed dorsally to compensate for the bending moment induced by the massive gut, the animal's vertical reach would be less than sometimes optimistically depicted. The height of the head at the maximum vertical reach of a tripodal pose, and the width of the feeding envelope in this posture, would depend on how nearly erect the sauropod could stand, on whether it settled some of its weight on the tail kangaroo-style, and on its stability, which would ultimately depend on the acuity of its neuromuscular coordination. The sauropod would need to integrate visual and vestibular signals to movement and to coordinate compensatory movements in order to prevent catastrophic instability, especially when attempting to extend the neck laterally as well as dorsally.

The relationship between sauropod feeding strategies and Mesozoic floral evolution is of interest in at least two ways. First, establishing a correspondence between sauropod tooth, skull, and neck forms and particular plant diets would clarify one of the most important types of energy flow among organisms in Jurassic and Cretaceous ecosystems. Second, at least some paleobotanists (Wing and Tiffney I987) and vertebrate paleontologists (Bakker I978) have suggested that "clear-cutting" of Jurassic and Early Cretaceous forests by sauropod herds may have been instrumental in creating ecological conditions that favored the origin of flowering plants.

The lithological unit containing the greatest diversity and abundance of sauropod fossils is the Upper Jurassic (and possibly Lower Cretaceous) Morrison Formation of western 
North America. Although floras of the Morrison Formation are not nearly as well preserved and understood as its sauropod fauna, they have been the object of many studies. Miller (I987) surveyed Morrison compression floras, mostly from Montana, and noted that cycadophytes, seed ferns, and ferns were generally more abundant than conifers and ginkgophytes. In their survey of Morrison taphonomy and paleoecology, Dodson et al. (I980) interpreted the Morrison depositional basin as a mostly arid, strongly seasonal, alluvial plain dissected by stream channels and occasional lakes. Rees et al. (2004) surveyed fossil plant distribution and taphonomy in the Late Jurassic Morrison Formation and concluded that the Morrison landscapes were savanna-like, dominated by herbaceous plants and short trees such as ginkgos and cycads, most of which were concentrated near rivers and lakes. Although taller conifers were part of the landscape, they appear to have been rare and confined to riparian corridors and small, isolated patches of forest (Rees et al. 2004).

Comparison of estimated browsing heights of various sauropod taxa with heights of extant members of plant clades that were abundant during the Jurassic and Cretaceous (fig. 6.I6) shows a striking correspondence between the mean browse heights of the sauropods and these generalized vegetation dimensions. The only sauropod taxa that appear to have had the capability of grazing on tall gymnosperms were Brachiosaurus and perhaps Camarasaurus. Studies of cranial anatomy and tooth form in both genera, and of tooth wear in Camarasaurus, suggest that they fed on more resistant plant material and possibly utilized more oral processing than was the case for diplodocids (Calvo I994; Fiorillo I998, Upchurch and Barrett I990). A survey of relative abundances of sauropods in the Morrison and Tendaguru sites (Rees et al. 2004) indicates that brachiosaurids are more abundant in the conifer-rich Tendaguru beds than the Morrison deposits. Upchurch and Barrett (I990) also put forth the hypothesis that differential wear on the upper and lower teeth of Diplodocus suggested that it utilized both low and high browsing. Diplodocids, along with the titanosaur clade Nemegtosauridae, have distinctive adaptations (including dorsally placed nostrils, a tooth comb restricted to the front of the jaws that was suitable for sieving or cropping, and a ventral inclination of the head relative to the horizontal axis of the braincase) that may have facilitated low browsing and, perhaps, even placement of the greater part of the heads underwater during feeding on aquatic plants (Parrish 2003).

One ecological paradox that has long been posited regarding the Jurassic sauropoddominated ecosystems is how they could support such a diverse and large assemblage of giant herbivores. One common model proposed involves herds of sauropods moving through forests and denuding them of vegetation as they trampled the trunks (e.g., Wing and Tiffney I987). Given that the default inclination for most sauropod necks appears to be one that positions the head close to the ground, perhaps it is more plausible that they were also feeding mostly at or near ground level. Lycopods and ferns appear to have been abundant in Mesozoic terrestrial ecosystems and, also, would have served as a rapidly growing, readily renewable food source, much like today's angiospermous grasses. This is not a new speculation, having been proposed for diplodocids (Krasilov I98I; Chatterjee and Zheng 1997), but it does potentially dovetail current thinking about sauropod functional morphology, late Mesozoic paleoecology, and plant physiology.

\section{CONCLUSIONS}

Since sauropods were first described, it has gradually become standard to reconstruct most of these dinosaurs as high browsers. The neutral pose of the presacral vertebral column can be reconstructed from the osteology of the articular facets of its component vertebrae. However, for all sauropods thus studied our analysis shows the following conditions: the dorsal portion of the vertebral column is 


\section{elevation}

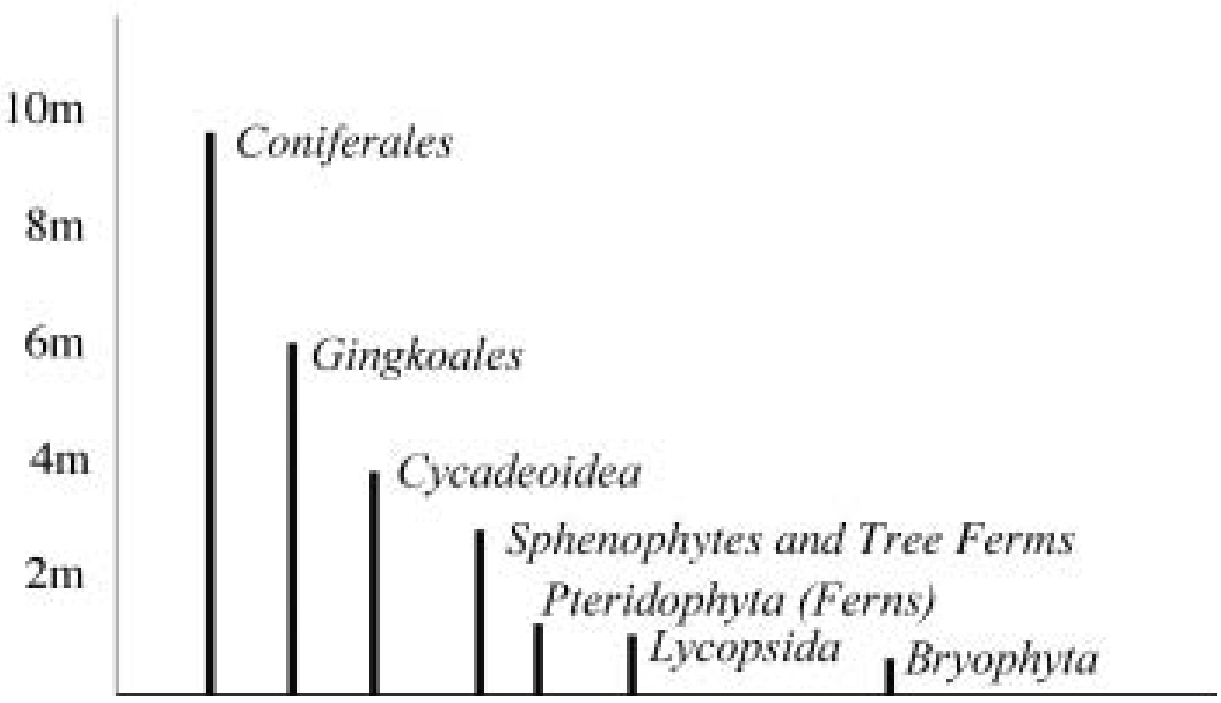

FIGURE 6.16. The bulk of the potential plant biomass in the middle Mesozoic, as exemplified here by the Morrison flora, appears to have been medium to low browse. Even the tallest conifers had the greatest amount of their foliage located in their bottom halves, and some of the fastest-growing and potentially most nutritious plants were ground cover (e.g., lycopods and small ferns). There was little vertical stratification in the flora to drive potential diversification among these herbivores. "Head-down" feeding by sauropods would be particularly apt for accessing the foliage and fructifications of groups like ferns, cycads, and ground cover. Even without reconstructing Brachiosaurus with a giraffelike neck, this sauropod was capable of BN feeding at about 5-6 m, while BD feeding by dorsiflexion of merely $3^{\circ}$ per joint would potentially raise the head $>9 \mathrm{~m}$ above ground level. Ventriflexion by about $8^{\circ}$ per joint proximally would place the head at ground level, permitting BV feeding that overlaps the mean feeding heights of camarasaurids and diplodocids. The diplodocids, in occasional BD feeding, could have overlapped the camarasaurid vertical range but were unique (with the possible exception of the later, nonsympatric Euhelopus) in their ability to feed in BV below mean surface level, a potential adaptation for aquatic feeding (see fig. 6.9). Contrary to the common expectation, vertical differentiation in sauropod feeding envelopes is not evident among these taxa, many of which were coeval and sympatric. The predominantly low mean feeding heights of these sauropods correspond closely to the height of the bulk of available browse. Although dental adaptations suggest clear diversity in feeding preferences among sauropods, there was little vertical stratification of floras to drive potential diversification among these herbivores.

arched, the cervical-dorsal transition is straight, negligible intrinsic curvature occurs in the posterior cervical vertebrae, and a shallow, concave-downward curvature occurs cranially. Most sauropods were medium to low browsers, with generally a "head-down" feeding angle. Although Brachiosaurus, possibly the tallest sauropod, is shown to have a nearly horizontal neck, it nonetheless held its head about $6 \mathrm{~m}$ above ground level. Therefore, Brachiosaurus and, perhaps, Camarasaurus (at the upward extent of its feeding envelope) appear to have been the only Jurassic sauropods clearly capable of feeding as "high browsers" on arborescent gymnosperms. Recent paleobotanical studies (e.g., Rees et al. 2004; J.T. Parrish et al., in press) suggest that the greatest abundance of forage in the sauropod-rich, Late Jurassic Morrison Formation was low- to mediumheight ground cover, which is consistent with the concept of most Morrison sauropods being low browsers.

\section{ACKNOWLEDGMENTS}

The authors are deeply appreciative of the contributions Dr. Jack McIntosh has made to the field of sauropod paleontology. Jack's devotion to sauropods, his encyclopedic familiarity with 
their fossil record, and his willingness to share that knowledge have enriched our research, and our lives, immensely. Jack has always expressed energetic support for our efforts to define the pose and movements of sauropods quantitatively. Seeing Jack dance a spontaneous Scottish jig in response to our poster at the Pittsburgh SVP quickened our hearts. Since then our work has been driven largely by a desire to induce a repeat performance. Ron Toth and Judy Parrish provided advice and photographs that were instrumental in the estimation of plant height estimates for figure 6.I6. Brian Curtice and Christopher McGowan provided photos of the Humboldt Museum sauropods that augmented those taken by J.M.P. Eric Wills provided important contributions to the programming of DinoMorph. Thanks go to Jim Madsen for providing us with the opportunity to manipulate a cast of Diplodocus carnegii. Heinrich Mallison provided three-dimensional data for the modeling of B. brancai. Matt Bonnan and Phil Platt provided valuable insights into sauropod limb posture. This work was supported in part by National Science Foundation Grant 0093929.

\section{LITERATURE CITED}

Alexander, R. M. I989. Dynamics of Dinosaurs and Other Extinct Giants. Columbia University Press, New York. I67 pp.

Bakker, R.T. I978. Dinosaur feeding behavior and the origin of flowering plants. Nature 274: 66I-663.

- I986. Dinosaur Heresies. William Morrow, New York. 48I pp.

Barrett, P. M., and Upchurch, P. I994. Feeding mechanisms of Diplodocus. GAIA IO: 195-204.

Beasley, Walter. I907. Diplodocus: the greatest of all earthly creatures. Scientific American 96(24): 49I-492.

Bonnan, M.F. 200I. The Evolution and Functional Morphology of Sauropod Dinosaur Locomotion. Ph.D. dissertation. Northern Illinois University, DeKalb, IL. 722 pp.

Calvo, J.O. I994. Jaw mechanics in sauropod dinosaurs. GAIA Io: I83-I94.

Chatterjee, S., and Zheng, Z. I997. The feeding strategies in sauropods. J. Vertebr. Paleontol. I7: 37A.
Christian, A., and Heinrich, W. -D. I998. The neck posture of Brachiosaurus brancai. Mittelungen Mus. Naturk. Berlin Geowissenschaften I: 73-80.

Christian, A., Heinrich, W. -D. and Golder, W. I999. Posture and mechanics of the forelimbs of Brachiosaurus brancai (Dinosauria: Sauropoda). Mittelungen Mus. Naturk. Berlin Geowissenschaften 2: 63-73.

Christiansen, P. 2000. Feeding mechanisms of the sauropod dinosaurs Brachiosaurus, Camarasaurus, Diplodocus, and Dicraeosaurus. Hist. Biol. I4: I37-I52.

Currie, P.J. I987. New approaches to studying dinosaurs in Dinosaur Provincial Park. In: Czerkas, S. J., and Olson, E. C. (eds.). Dinosaurs Past and Present. Vol. II. University of Washington Press, Seattle. Pp. Ioo-II7.

Curry Rogers, K., and Forster, C.A. 200I. The last of the dinosaur titans: a new sauropod from Madagascar. Nature 4I2: 530-534

Czerkas, S. A., and Czerkas, S. J. I99I. Dinosaurs: A Global View. Mallard Press, New York. 247 pp.

Daag, A. I., and Foster, J. B. I976. The Giraffe: Its Biology, Behavior, and Ecology. Van Nostrand Reinhold, New York. 21o pp.

Dodson, P. M. I990. Sauropod paleoecology. In: Weishampel, D. B., Dodson P., and Osmolska, H. (eds.). The Dinosauria. University of California Press, Berkeley. Pp. 402-407.

Dodson, P.M., Behernsmeyer, A. K., Bakker, R.T., and McIntosh, J.T. I980. Taphonomy and paleoecology of the dinosaur beds of the Jurassic Morrison Formation. Paleobiology 6: 208-232.

Farlow, J. O. I987. Speculations about the diet and digestive physiology of herbivorous dinosaurs. Paleobiology 13: 60-72.

Fiorillo, A.R. I998. Dental microwear patterns of sauropod dinosaurs Camarasaurus and Diplodocus: evidence for resource partitioning in the Late Jurassic of North America. Hist. Biol. I3: I-I6.

Gauthier-Pilters, H., and Daag, A. I. I98I. The Camel, Its Ecology, Behavior and Relationship to Man. University of Chicago Press, Chicago. 208 pp.

Gilmore, C.W. I925. A nearly complete articulated skeleton of Camarasaurus, a saurischian dinosaur from the Dinosaur National Monument. Mem. Carnegie Mus. Io: 347-384.

Gilmore, C.W. I936. The osteology of Apatosaurus with special reference to specimens in the Carnegie Museum. Mem. Carnegie Mus. II: I75-300.

Hatcher, J. B. I90ı. Diplodocus (Marsh): its osteology, taxonomy, and probable habits, with a reconstruction of the skeleton. Mem. Carnegie Mus. I: I-63. 
Holland, W.J. I9o6. The osteology of Diplodocus Marsh. Mem. Carnegie Mus. 2: 225-278.

Janensch, W. I929. Die Wirbelsäule der Gattung Dicraeosaurus hausemanni. Palaeontographica 3 (Suppl. 7): 39-I33.

Janensch, W. I950a. Die Wirbelsäule von Brachiosaurus brancai. Palaeontographica (Suppl. 7) 3: 27-93.

Janensch, W. I950b. Die Skelettrekonstrucktion von Brachiosaurus brancai. Palaeontographica 3 (Suppl. 7): 95-103

Janensch, W. I96I. Die Gliedmaszen und Gliedmaszengürtel der Sauropoden der TendaguruSchichten. Palaeontographica (Suppl. 7)3: I77-235.

Krasilov, V.A. I98I. Changes of Mesozoic vegetation and the extinction of the dinosaurs. Paleogeog. Paleoclimatol. Palaeoecol. 34: 207-224.

Leuthold, B. I977. African Ungulates: A Comparative Review of Their Ethology and Behavioral Ecology. Springer Verlag, Berlin. 307 pp.

Leuthold, B., and Leuthold, W. I972. Food habits of giraffe in Tsavo National Park, Kenya. East Afr Wildl. J. IO: I29-I4I.

Martin, J. I987. Mobility and feeding of Cetiosaurus: Why the long neck? Occas. Paper Tyrell Mus. Paleontol. 3: I5O-I55.

McGinnis, H.J. I982. Carnegie's Dinosaurs. Carnegie Museum of Natural History, Pittsburgh, PA. I29 pp.

McIntosh, J., M. K. Brett-Surman and J. O. Farlow. I997. Sauropods. In: Farlow, J. O., and BrettSurman, M.K. (eds.). The Complete Dinosaur. Indiana University Press, Bloomington. Pp. 264-290.

Miller, C. M. I987. Land plants of the northern Rocky Mountains before the appearance of flowering plants. Ann. Ma. Bot. Garden 74: 692-706.

Osborn, H. F., and Mook, C.C. I92I. Camarasaurus, Amphicoelias, and other sauropods of Cope. Mem. Am. Mus. Nat. Hist. 3: 247-287.

Owen-Smith, R. N. I988. Megaherbivores: The Influence of Very Large Body Size on Ecology. Cambridge University Press, Cambridge. 369 pp.

Parrish, J. M. 2003. Mapping ecomorphs onto sauropod phylogeny. J. Vertebr. Paleontol. Suppl. 23(3): $85 \mathrm{~A}-86 \mathrm{~A}$.

Parrish, J. M., and Stevens, K.A. I998. Undoing the death pose: Using computer imaging to restore the posture of articulated dinosaur skeletons. J. Vertebr. Paleontol. Suppl.r8: 69A.

- 2002a. Neck mobility in long-necked vertebrates: from modern mammals to sauropods. J. Morphol. 248: 270.

. 2002b. Rib angulation, scapular position, and body profiles in sauropod dinosaurs. J. Vertebr. Paleontol. Suppl. 22(3): 95A.
Paul, G. S. I987. The science and art of restoring the life appearance of dinosaurs and their relatives: a rigorous how-to guide. In: Czerkas, S. J., and Olson, E. C., (eds.). Dinosaurs Past and Present. Vol. II. University of Washington Press, Seattle. Pp. 5-49.

- 2000. Restoring the life appearance of dinosaurs. In: Paul, G.S. (ed.). The Scientific American Book of Dinosaurs. Bryon Press and Scientific American, New York. Pp. 78-106.

Pellew, R. I984. The feeding ecology of a selective browser, the giraffe (Giraffa camelopardalis tippelskirchi). J. Zool. 202: 57-8I.

Pincher, C. I949. Evolution of the giraffe. Nature I64: 29-30.

Rees, P.M., Noto, C. R., Parrish, J.M., and Parrish, J.T. 2004. Late Jurassic climates, vegetation, and dinosaur distributions. J. Geol. II2: 643-653.

Sereno, P.C., Beck, A. L., Moussa, B., Dutheil, D., Larsson, H. C. E., Lyon, G. H., Sadlier, R. W., Sidor, C.A., Varrichio, D. J., Wilson, G.P., and Wilson, J.A. I999. Cretaceous sauropods from the Sahara and the uneven rate of skeletal evolution among dinosaurs. Science 286: I342-I347.

Simmons, R., and Scheepers, L. I996. Winning by a neck: sexual selection in the evolution of the giraffe. Am. Nat. I48: 77I-786.

Stevens, K. A. 2002. DinoMorph: parametric modeling of skeletal structures. Senckenbergiana Lethaea 82(I): 23-34.

Stevens, K. A., and Parrish, J. M. I999. Neck posture and feeding habits of two Jurassic sauropod dinosaurs. Science, 284: 798-800.

- 2005a. Neck posture, dentition, and feeding strategies in Jurassic sauropod dinosaurs. In: Carpenter, K., and Tidwell, V. (eds.). Thunder Lizards: The Sauropodomorph Dinosaurs. University of Indiana Press, Bloomington (in press).

- 2005b. The intrinsic curvature of sauropod necks (Saurischia: Dinosauria) (in preparation).

Stevens, K.A., and Wills, E. D. 200I. Gracile versus robust cervical vertebral designs in sauropods. J. Vertebr. Paleontol. Suppl. 2I(3): I04A.

Thulborn, R.A. I990. Dinosaur Tracks. Chapman and Hall, London. 430 pp.

Upchurch, P., and Barrett, P. M., 2000. The evolution of sauropod feeding mechanisms. In: Sues, H. D. (ed.). Evolution of Herbivory in Terrestrial Vertebrates. Cambridge University Press, Cambridge. pp. 79-122.

Walther, F. I969. Flight behavior and avoidance of predators in Thompson's gazelle (Gazella thomsoni Gunther, I884). Behaviour 34: I84-22I.

Wedel, M. J., and Sanders, R. K. I999. Comparative morphology and functional morphology of the 
cervical series in Aves and Sauropoda. J. Vertebr. Paleontol. I9: 83A.

Wilhite, R. 2003. Digitizing large fossil skeletons for three-dimensional applications. Paleontol. Electronica 5(I): I-IO

Wilson, J.A., and Sereno, P. C. I998. Early evolution and higher-level phylogeny of sauropod dinosaurs. Soc. Vertebr. Paleontol. Mem. 5: I-68.

Wiman, C. I929. Die Kriede-dinosaurier aus Shantung. Palaeontol. Sinica (Ser. C) 6: I-67.
Wing, S. L., and Tiffney, B.H. I987. The reciprocal interaction of angiosperm evolution and tetrapod herbivory. Rev. Paleobot. Palynol. 50: 179-210.

Woolnough, A.P., and du Toit, J.T. 200I. Vertical zonation of browse quality in tree canopies exposed to a size-structured guild of African browsing ungulates. Oecologia I29: 585-590.

Young, T., and Isbell, L. I99I. Sex differences in giraffe feeding ecology: Energetic and social constraints. Ethology 87: 79-89. 